\title{
Contribution of Different Limb Controllers to Modulation of Motor Cortex Neurons during Locomotion
}

\author{
Pavel V. Zelenin, ${ }^{1}$ Tatiana G. Deliagina, ${ }^{1}$ Grigori N. Orlovsky, ${ }^{1}$ Anastasia Karayannidou, ${ }^{1,2}$ Namrata M. Dasgupta, ${ }^{2}$ \\ Mikhail G. Sirota, ${ }^{2}$ and Irina N. Beloozerova ${ }^{2}$ \\ ${ }^{1}$ Department of Neuroscience, Karolinska Institute, Stockholm, SE-171 77, Sweden, and ${ }^{2}$ Barrow Neurological Institute, Phoenix, Arizona 85013
}

\begin{abstract}
During locomotion, neurons in motor cortex exhibit profound step-related frequency modulation. The source of this modulation is unclear. The aim of this study was to reveal the contribution of different limb controllers (locomotor mechanisms of individual limbs) to the periodic modulation of motor cortex neurons during locomotion. Experiments were conducted in chronically instrumented cats. The activity of single neurons was recorded during regular quadrupedal locomotion (control), as well as when only one pair of limbs (fore, hind, right, or left) was walking while another pair was standing. Comparison of the modulation patterns in these neurons (their discharge profile with respect to the step cycle) during control and different bipedal locomotor tasks revealed several groups of neurons that receive distinct combinations of inputs from different limb controllers. In the majority (73\%) of neurons from the forelimb area of motor cortex, modulation during control was determined exclusively by forelimb controllers (right, left, or both), while in the minority (27\%), hindlimb controllers also contributed. By contrast, only in 30\% of neurons from the hindlimb area was modulation determined exclusively by hindlimb controllers (right or both), while in $70 \%$ of them, the controllers of forelimbs also contributed. We suggest that such organization of inputs allows the motor cortex to contribute to the right-left limbs' coordination within each of the girdles during locomotion, and that it also allows hindlimb neurons to participate in coordination of the movements of the hindlimbs with those of the forelimbs.
\end{abstract}

\section{Introduction}

During locomotion, activity of neurons in the motor cortex is profoundly modulated in the rhythm of stepping (Armstrong and Drew, 1984a,b; Beloozerova and Sirota, 1985, 1993a,b; Drew, 1993). It has been shown that this modulation is necessary for accurate stepping on uneven terrain, when adjustments of the limb trajectory are required to overstep an obstacle or to place the foot on a definite spot on the ground (Beloozerova and Sirota, 1988, 1993a; Drew, 1988, 1991). While at least a part of modulation during complex locomotion tasks seems to arise from visuomotor integration centers in the brain that guide the limb according to visually perceived features of the environment (Drew et al., 1996, 2004; Beloozerova and Sirota, 2002, 2003), the sources of modulation during simple locomotion on a flat surface are unclear.

In decerebrated cats, all major subcortical descending tracts (vestibulospinal, reticulospinal, and rubrospinal) ex-

Received Dec. 14, 2010; revised Jan. 31, 2011; accepted Feb. 4, 2011.

Author contributions: P.V.Z., T.G.D., G.N.O., A.K., N.M.D., M.G.S., and I.N.B. designed research; P.V.Z., T.G.D., G.N.O., A.K., N.M.D., M.G.S., and I.N.B. performed research; P.V.Z., T.G.D., G.N.O., A.K., N.M.D., M.G.S., and I.N.B. analyzed data; P.V.Z., T.G.D., G.N.O., A.K., N.M.D., M.G.S., and I.N.B. wrote the paper.

This study was supported by Swedish Research Council (M) Grant 21076 to P.V.Z., National Institutes of Health (NIH) Grant R01 NS-049884, Swedish Research Council (M) Grant 11554, the Erik and Edith Fernströms Foundation, and the Karolinska Institute Foundation to T.G.D., Undergraduate Summer Student Research Program at Barrow Neurological Institute to N.M.G., and NIH Grants R01 NS-39340 and R01 NS-058659 to I.N.B. We are grateful to Erik E. Stout for analysis of kinematics data and to Peter Wettenstein for excellent engineering assistance.

Correspondence should be addressed to Dr. Pavel V. Zelenin, Department of Neuroscience, Karolinska Institute, SE-171 77, Stockholm, Sweden. E-mail: pavel.zelenin@ki.se.

DOI:10.1523/JNEUROSCI.6511-10.2011

Copyright $\odot 2011$ the authors $\quad 0270-6474 / 11 / 314636-14 \$ 15.00 / 0$ hibit locomotion-related modulation of their activity, and integrity of the cerebellum is required for this modulation to occur (Orlovsky, 1970, 1972a,b). The locomotion-related modulation in the cerebellum is caused by input from the spinal cord, which reflects both the activity of spinal networks generating the locomotion rhythm and the signals from limb somatosensory receptors (Arshavsky et al., 1972, 1984, 1986). The motor cortex gives rise to the pyramidal tract, and like other descending systems, may receive modulating signals from the cerebellum via the ventrolateral thalamus (Beloozerova and Sirota, 1988, 2002). It may also receive information from limb afferents via the somatosensory cortex (Waters et al., 1982; Mori et al., 1989) and/or directly from thalamic relays (Asanuma et al., 1979; Yen et al., 1991; Craig, 2008).

These data suggest that during simple locomotion, the spinal locomotor mechanisms represent an ultimate source of locomotion-related information for all supraspinal centers, including the motor cortex. Revealing the specific routes by which this information reaches the motor cortex still requires considerable research. The present study was devoted to a principal question: what is the contribution of different limb controllers (locomotor mechanisms of individual limbs) to the periodic modulation of the motor cortex neurons during locomotion?

To answer this question, we compared activity of individual neurons from the forelimb and hindlimb representations of the cat motor cortex during five locomotor tasks that differed in the combination of stepping limbs-when all four limbs were walking, as well as when only one pair of limbs was walking, while another pair was standing. We have found that typically two or 
more controllers contributed to the modulation in each neuron (not merely the controller of the corresponding contralateral limb). Moreover, we have found that, while the forelimb-related neurons were most often driven exclusively by the forelimb controllers, the hindlimb-related neurons often also received inputs from forelimb controllers in addition to inputs from hindlimbs. We discuss functional implications of such organization of locomotion-related inputs to the motor cortex.

A brief account of this study was published in abstract form (Zelenin et al., 2010).

\section{Materials and Methods}

Recordings were obtained from three adult cats, two males and one female. Some of the methods have been described (Beloozerova et al., 2005; Prilutsky et al., 2005; Karayannidou et al., 2008) and will be reported briefly here. All experiments were conducted at Barrow Neurological Institute in accordance with National Institutes of Health guidelines and with the approval of the Barrow Neurological Institute Animal Care and Use Committee.

Surgical procedures. Surgery was performed under isoflurane anesthesia using aseptic procedures. Bipolar EMG electrodes (flexible Tefloninsulated stainless-steel wires) were implanted bilaterally into two forelimb muscles: $\mathrm{m}$. brachialis (Bra, elbow flexor) and $\mathrm{m}$. triceps brachii (Tric, elbow extensor), and into four hindlimb muscles: $\mathrm{m}$. tibialis anterior (Tib, ankle flexor), m. gastrocnemius lateralis (Gast, ankle extensor), $\mathrm{m}$. vastus lateralis (Vast, knee extensor), and m. gluteus medius (Glut, hip extensor and abductor).

The skin and fascia were removed from the dorsal surface of the skull. At 10 points around the circumference of the head, stainless steel screws were screwed into the skull and connected together with a wire; the screw heads and the wire were then inserted into a plastic cast to form a circular base. Later, while searching for neurons before locomotion tests, awake cats were rigidly held by this base. The base was also used for fixation of connectors, a miniature microdrive, a preamplifier, contacts for stimulating electrodes, and a protective cap.

A portion of the skull and dura above the left motor cortex were removed. The motor cortex was identified by the surface features and photographed (see Fig. $2 A$ ). The aperture was then covered by a plastic plate with many small holes filled with wax. The plate was fastened to the surrounding bone. Two 26 gauge hypodermic guide tubes were implanted vertically above the medullary pyramids, at the Horsley-Clarke coordinates (P10, L0.5) and (P10, L1.5), at the depth of V0 for subsequent insertion of stimulating electrodes into the pyramidal tract.

Identification of cortical motor area. Experiments were initiated after several days of recovery. The animal was positioned on a table equipped with a foam rubber pad and head-restraining device. After the cat rested on this pad for several minutes, the base attached to the skull during surgery was fastened to the head-restraining frame so that the resting position of the head was approximated. This procedure minimized stress on the neck while the head was immobilized. Over several days, a number of sessions of increasing duration were used to accustom the cat to the head restraint.

The motor cortex was mapped using multiple-unit recording and microstimulation techniques. A detailed description of the area of recording and the methods of its identification was given earlier (Beloozerova et al., 2005). In brief, for identification of forelimb and hindlimb representations of motor cortex, three approaches have been used. First, somatic receptive fields were mapped by manual application of stimuli to the skin and fur, by palpation of muscles and their tendons, and by passive movements of joints while simultaneously observing the multiple-unit neuronal responses. Second, activity of the neurons during active withdrawal and reaching movements of the animal was noted. Third, in selected tracks microstimulation (trains of ten $25 \mu \mathrm{A}$ cathodal pulses at $350 \mathrm{~Hz}$, with each pulse of $0.2 \mathrm{~ms}$ ) was applied using a platinum-tungsten quartz insulated microelectrode with impedance of $200-500 \mathrm{k} \Omega$. Effects of microstimulation were evaluated by observation of evoked movements, by body part palpation, and/or by recording responses from muscles with implanted EMG electrodes. The area immediately adjacent to and inside

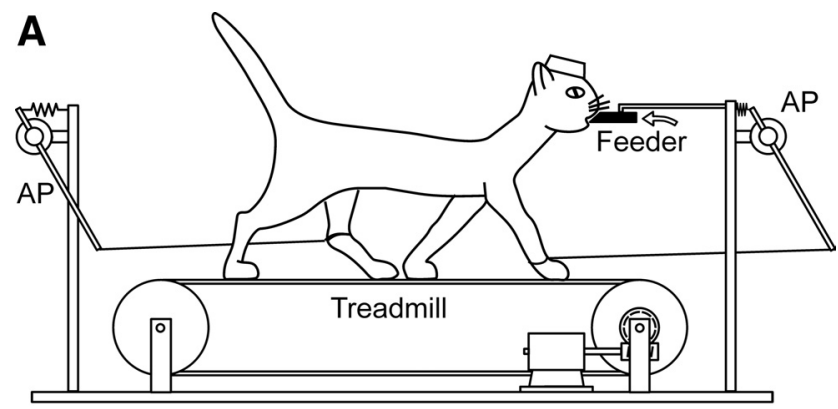

B
Test $2 F$

\section{Test $2 \mathrm{~F} 2 \mathrm{H}$}





Test $2 R$

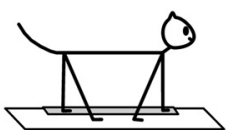

Test $2 \mathrm{H}$

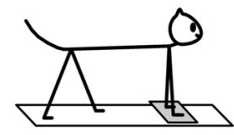

Test $2 L$

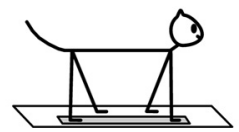

Figure 1. Locomotor tasks. $A$, The cat was walking on the moving treadmill belt. The AP position of the limbs during stepping was recorded by mechanical sensors. $B$, Different locomotor tests. In the control test, the cat walked with all four limbs (Test 2F2H). In the other tests, the cat walked with forelimbs only (Test 2F), with hindlimbs only (Test 2H), with right limbs only (Test 2R), or with left limbs only (Test 2L), while the other limbs were standing on a stationary platform. During all tests, the cat was continuously licking food from the feeder (black bar in $\boldsymbol{A}$ ).

the lateral half of the cruciate sulcus in the cat is considered to be the motor cortex. This is based on considerable body of data obtained by means of inactivation, stimulation, and recording techniques (Nieoullon and Rispal-Padel, 1976; Vicario et al., 1983; Armstrong and Drew, 1985; Beloozerova and Sirota, 1993a; Drew, 1993), as well as on histological considerations (Ghosh, 1997; Myasnikov et al., 1997). The forelimb and hindlimb representations in the left motor cortex and microelectrode entry points on the cortical surface are schematically shown in Figure 2, A and $D-G$.

Cell recording and identification. Neuronal activity was recorded extracellularly from the left motor cortex using commercially available tungsten varnish insulated electrodes Frederick Haer \& Co). The custommade microdrive $(5 \times 5 \times 30 \mathrm{~mm}, 2.5 \mathrm{~g})$ was permanently fastened to the base on the cat's head, and used to advance the microelectrode (see Fig. $2 B$ ). The impedance of the electrodes was 2-4 M $\Omega$. After the electrode reached the depth of the cortex, where the responses of neurons to limb movements could be clearly observed (presumably layer V), two $200 \mu \mathrm{m}$ platinum-iridium wires were slowly inserted and lowered into the medullar pyramid through the guide tubes (implanted during surgery). Pulses of graded intensity $(0.2 \mathrm{~ms}$ duration, up to $0.5 \mathrm{~mA})$ were delivered through this bipolar electrode. The wires were fixed at the positions that were most effective in eliciting antidromic responses in neurons of the motor cortex, and served as the pyramidal tract-stimulating electrode for all following experiments. The criterion for identification of antidromic responses was the test for collision of spikes (see Fig. 2C) (Bishop et al., 1962; Fuller and Schlag, 1976). The waveform analysis was employed to discriminate and identify the spikes of a single neuron using the Power1401/Spike2 system waveform-matching algorithm. All encountered neurons were tested for antidromic activation before, during, and after each locomotor test, using identical current pulses and criterion. The neurons with a stable response latency and spike shape, which satisfied the collision test, were considered pyramidal tract neurons (PTNs). The somatic receptive fields of neurons were examined in resting animals under conditions of head restraint. Stimulation was produced by palpation of muscle bellies, tendons, etc., as well as by passive movements of joints.

Locomotor tests. During search for the neurons, the animal was sitting with its head fixed to a stationary frame. After a neuron was found and 
identified, the animal was positioned on the belt of the treadmill (Fig. $1 A$ ). The belt gradually attained the speed of $0.5 \mathrm{~m} / \mathrm{s}$, maintained it for 1-1.5 min, and then slowly stopped. Cats were trained to perform different locomotor tasks (see below), and were rewarded by a paste-like food continuously ejected from a feeder (Karayannidou et al., 2008). The feeder (a plastic tube of $18 \mathrm{~mm}$ outer diameter and 6 $\mathrm{mm}$ inner diameter) was positioned in front of the cat at a height of $21-23 \mathrm{~cm}$ (Fig. $1 \mathrm{~A}$ ). It took a few weeks for the cats to get acquainted with walking on the treadmill. After this training period, they were easily engaged in all locomotion tasks. The cats maintained a stable position in relation to the treadmill, which allowed them to hold the mouth against the feeder and to keep licking food during walking (Karayannidou et al., 2009). Five forms of locomotion were tested (Fig. $1 \mathrm{~B}$ ): Test 2F2H (control)—all four limbs walk; Test $2 \mathrm{~F}$ - the forelimbs walk, while the hindlimbs stand on a stationary platform; Test $2 \mathrm{H}$ - the hindlimbs walk, while the forelimbs stand on a stationary platform; Test $2 \mathrm{R}$ - both right limbs walk, while both left limbs stand on a stationary platform; and Test 2L-both left limbs walk, while both right limbs stand on a stationary platform.

Test $2 \mathrm{~F} 2 \mathrm{H}$ was performed for all neurons. The other tests, however, were performed for the majority but not all neurons. The numbers of neurons for which a particular test was performed are indicated in Figure 7. In Figure 11, $C$ and $D$, and Table 2, only those neurons that were tested in all five tests are presented.

Four mechanical sensors monitored the anterior-posterior (AP) position of each limb during walking (Karayannidou et al., 2008); two of the sensors (attached to the right forelimb and the left hindlimb) are shown in Figure $1 \mathrm{~A}$. In selected experiments, limb movements were also monitored using Visualeyez System (3D Real Time Motion Capture and Analysis System, Phoenix Technologies). It detects positions of light-emitting photodiodes in 3D space and makes calculations of various kinematical parameters. The photodiodes were attached to the skin projections of the main limb joints either on the right forelimb or on the right hindlimb (see Fig. 4). The frequency of frame sampling was $250 \mathrm{~Hz}$. In some trials, cat's movements were also videotaped (30 frames/s).

Data collection and processing. Signals from the microelectrode preamplifier, from EMG preamplifiers, and from the position sensors were amplified and filtered $(300-10,000 \mathrm{~Hz}$

bandpass for neurons and 30-1000 Hz bandpass for EMG and sensors) using a CyberAmp 380 (Molecular Devices) amplifier, digitized with sampling frequencies of $30 \mathrm{kHz}$ (microelectrode), $3 \mathrm{kHz}$ (EMGs), and $400 \mathrm{~Hz}$ (sensors), displayed on the screen, and recorded to the disc of a computer using data-acquisition software (Power-1401/Spike2, CED). After digitization, the EMG signals were rectified and smoothed by filters with a time constant of $50 \mathrm{~ms}$. An example of untreated data recording is shown in Figure $2 H$.

All neurons were examined in Test $2 \mathrm{~F} 2 \mathrm{H}$, and most of them were also examined in four other tests. The activity of neurons was typically modulated in the rhythm of stepping movements (Fig. $2 H$ ). To characterize this modulation, the phase histogram of neuronal activity in a step cycle

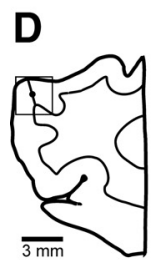


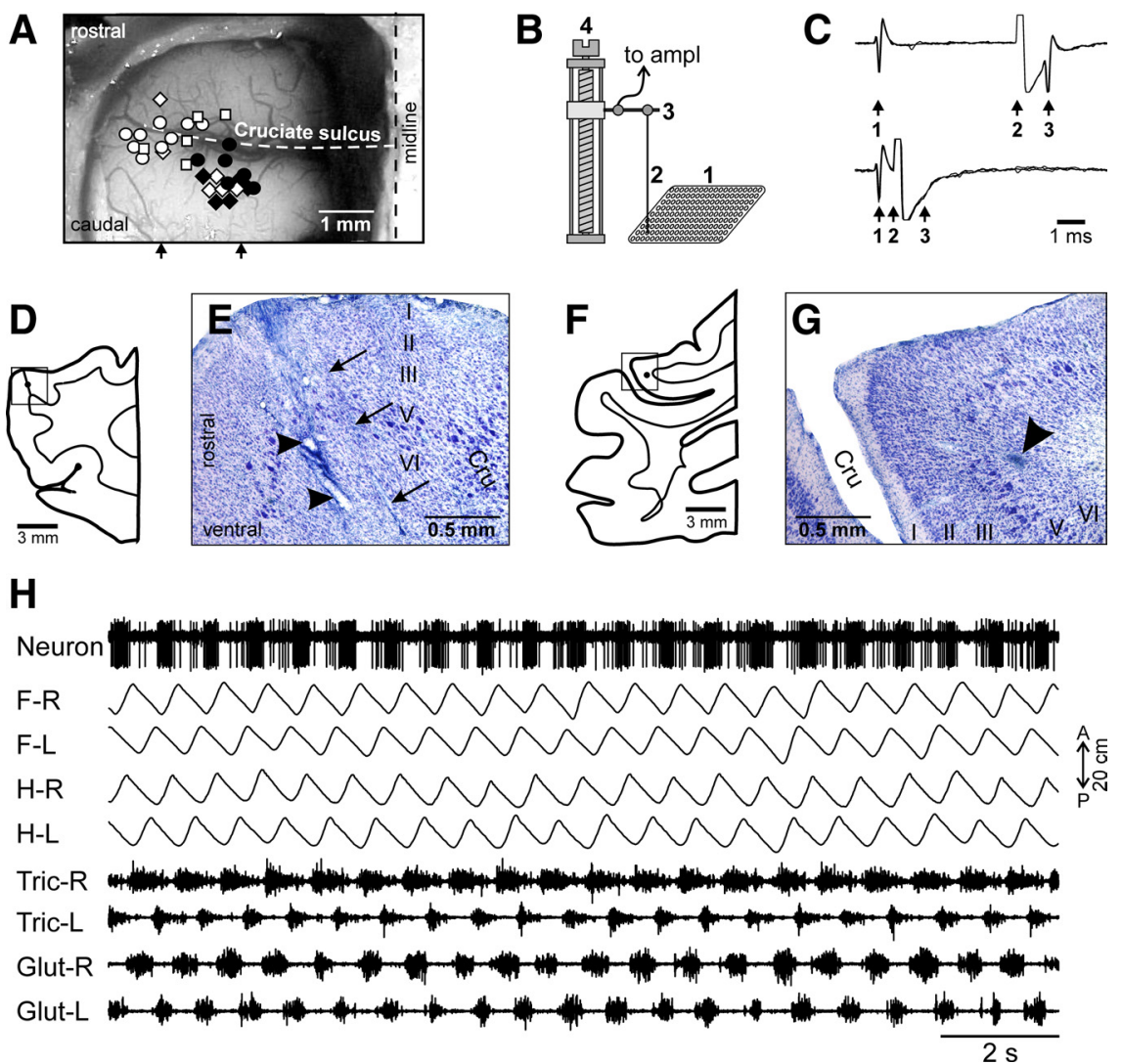

Figure 2. Areas of the motor cortex studied. $A$, Areas of recording within representations of the forelimb and hindlimb in the left (forelimb-related neurons in the track) or black (hindlimb-related neurons in the track) symbols on a photograph of cat 2 cortex. rrows indicate approximate mediolateral positions of parasagittal sections shown in $\mathbf{D}-\mathbf{G}$. $\boldsymbol{B}$, The method of insertion and



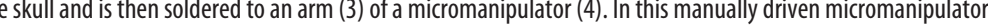

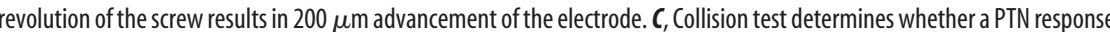
idromic. Top trace, A PTN spontaneously discharges (arrow 1), and pyramidal tract neuron is stimulated $\sim 5$ ms later (arrow fimulated $\sim 0.5$ ms later (arrow 2). The PTN does not respond (arrow 3) because in $0.5 \mathrm{~ms}$ its spontaneous spike was still en route ramidal tract, and thus collision/nullification of spontaneous and evoked spikes occurred. D, Drawing of a parasagittal section position of the reference electrolytic lesion is shown by a black circle. The square approximately indicates the area shown in the icrograph in $E$. E, Photomicrograph of a parasagittal section through the motor cortex, stained with cresyl violet. Layers of to a track made by a microelectrode. Arrowheads point to the reference electrolytic lesions. $\boldsymbol{F}$, Drawing of a parasagittal through the caudal bank of the cruciate sulcus. The position of the reference electrolytic lesion is shown by a black circle. The the motor cortex, stained with cresyl violet. Layers of the cortex are numbered. An arrowhead points to the reference electrolytic Clusters of giant cells in layer $V$ that are characteristic for area $4 \gamma$ are visible around the lesion. Scales in $\mathbf{D}-\mathbf{G}$ were not limbs (F-R, right forelimb; F-L, left forelimb; H-R, right hindlimb; H-L, left hindlimb) and four muscles (Tric-R, right triceps; Tric-L, left triceps; Glut-R, right gluteus; Glut-L, left gluteus) during quadrupedal locomotion.

was created. Because of some variability in the duration and structure of step cycles within a test and between the tests (see Results), we divided the step cycle into four periods and normalized them separately. These periods for Tests $2 \mathrm{~F} 2 \mathrm{H}, 2 \mathrm{~F}$, and $2 \mathrm{H}$ are shown in Figure $3 A-C$ : (1) the right limb swing; (2) the early right limb stance ending when the left limb begins swing; (3) the right limb midstance while the left limb is in swing; and (4) the late right limb stance starting when the left limb touches ground. In Test $2 \mathrm{R}$ (Fig. 3D), the first period was the right limb swing (as in Fig. $3 A-C$ ), but since the left limbs were standing, the third period was set equal to the first period and starting from the middle of the right limb cycle. Similarly, in Test $2 \mathrm{~L}$ the third period was the left limb swing, and the first period was set equal to the third period and starting from the 
middle of the left limb cycle (Fig. 3E). Each of the four periods was normalized to one quarter of the cycle. Such normalization ensured that muscular and neuronal activity during a definite phase (swing or stance) in one test was compared to activity during the same phase in all other tests, or when these characteristics were compared in different steps within the same test. The range of phase values for the first period was from 0 to 0.25 , for the second period from 0.25 to 0.5 , for the third period from 0.5 to 0.75 , and for the fourth period from 0.75 to 1 (see Figs. 5, 6, 9, 10).

The spike time sequence was converted to instantaneous rate versus time and then to instantaneous rate versus phase ( 250 points in each of the four periods of the cycle). The dependence of the instantaneous rate on the phase was averaged over all steps of a given test. Then the histogram was smoothed (sliding window, 50 bins) to remove high-frequency noise. Examples of the resulting histograms are shown in Figure 10. Phase histograms of the same type were also created for joint angles (see Fig. 5) and rectified EMG signals (see Fig. 6).

To evaluate the depth and the phase of step-related modulation of neuronal activity, we used the best two-level rectangular fit for instantaneous frequency within the step cycle; the upper level was defined as a "burst," and the lower level as an "interburst period" (see Fig. 10) (Karayannidou et al., 2009). The activity of neurons was considered modulated if the burst frequency was significantly different from the interburst frequency ( $t$ test, $p<0.05$ ). For the modulated neurons, the coefficient of frequency modulation was calculated using the formula $K_{\bmod }=\left(f_{\mathrm{B}}-\right.$ $\left.f_{\mathrm{IB}}\right) / f_{\mathrm{B}}$, where $f_{\mathrm{B}}$ and $f_{\mathrm{IB}}$ are the burst and interburst frequencies, respectively. The middle of the burst was taken for the preferred phase of the neuronal activity $\Phi_{\text {pref }}$. We also calculated the mean frequency of the neuronal activity $f_{\mathrm{M}}$ (see Fig. 10).

To evaluate the degree of similarity between modulation patterns of the same neuron in two different tests, we used an ordinary method of correlation analysis (see, e.g., Zar, 1974), but calculated the coefficient of correlation (CC) not between two random variables but between two functions (phase histograms) obtained in these tests. This analysis reveals covariations of the two functions, i.e., parallel changes of the instantaneous discharge frequency within the cycle, while dismissing differences between mean frequencies and depths of modulation. Examples of neuronal discharges recorded during different tasks and then compared using this method are shown in Figure 10. We also used this type of analysis for comparison of phase profiles of angles in individual joints of the forelimb and hindlimb during two different tests (see Fig. 5), as well as for comparison of EMG patterns of the same muscle in two different tests (see Fig. 6).

For each neuron, the phase histograms can be built in relation to the forelimb or hindlimb movements. We always used the "own" girdle movement if the "own" girdle was involved in walking. However, to build the phase histograms in the tests in which the neuron's "own" girdle did not walk, we had to use movements of the other girdle for reference. That is why in Test $2 \mathrm{~F} 2 \mathrm{H}$, for each neuron we built two phase histograms, using either forelimb movements or the hindlimb movements for reference, and one of these histograms was compared to the corresponding histogram from a bipedal test. For example, for a hindlimb area neuron, we used movements of the forelimbs to define swing and stance phases in Test $2 \mathrm{~F}$ and Test $2 \mathrm{~F} 2 \mathrm{H}$; and movements of the hindlimbs in Test $2 \mathrm{H}$, Test $2 \mathrm{R}$, Test $2 \mathrm{~L}$, and (once more) in Test $2 \mathrm{~F} 2 \mathrm{H}$. To calculate CC in Test $2 \mathrm{~F}$, the histogram for Test $2 \mathrm{~F} 2 \mathrm{H}$ in the forelimb cycle was used. To calculate CC for Test $2 \mathrm{H}$, Test $2 \mathrm{R}$, and Test $2 \mathrm{~L}$, we used the histogram for Test $2 \mathrm{~F} 2 \mathrm{H}$ in the hindlimb cycle.

All quantitative data that characterize populations are presented as the mean \pm SD. Statistical comparisons were made using $t$ test, with the significance level $p=0.05$.

Histological procedures. At the termination of experiments, cats were deeply anesthetized with pentobarbital sodium. Several reference lesions were made in the region of motor cortex from which neurons were sampled. Cats were then perfused with isotonic saline followed by a $10 \%$ formalin solution. Frozen brain sections of $50 \mu \mathrm{m}$ thickness were cut in the regions of recording and stimulating electrodes. The tissue was stained for Nissl substance with cresyl violet. The position of stimulation electrodes in the medullar pyramids was verified by observation of elec-
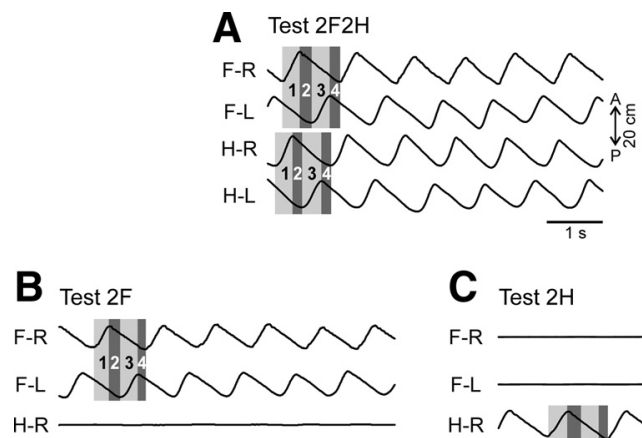

C Test $2 \mathrm{H}$

F-R



$\mathrm{H}-\mathrm{L}$



E Test 2L
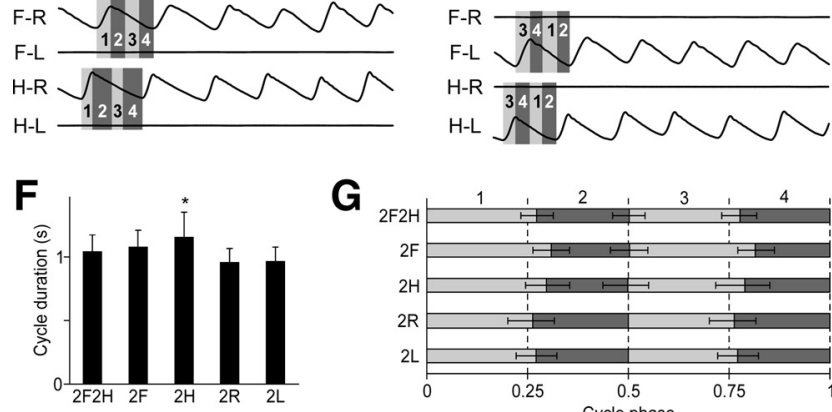

G

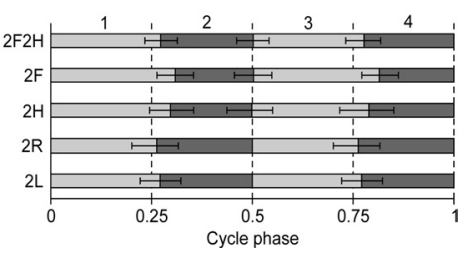

Figure 3. General kinematics of different locomotor tasks. $\boldsymbol{A}-\boldsymbol{E}$, Limb movements in different tests. Four periods were recognized in each locomotor cycle for each girdle: the right limb swing (1), the period after the right limb swing but before the left limb swing (2), the right limb midstance lasting while the left limb is in swing (3), and the period after the left limb swing but before the right limb swing (4). Because in Test $2 R$ and Test $2 \mathrm{~L}$ one of the limbs in each girdle did not walk, its swing duration was set equal to the swing duration of the opposite limb of the girdle and starting from the middle of the step cycle $(\boldsymbol{D}, \boldsymbol{E})$. $\boldsymbol{F}$, The average cycle duration in different tests (mean $\pm S D$, significant difference relative to Test $2 \mathrm{~F} 2 \mathrm{H}$ is indicated by an asterisk). $\mathbf{G}$, The cycle structure, i.e., the parts of the cycle occupied by each of the four periods in different tests, averaging over all trials of each test (mean $\pm S D$ ). Note that the periods were close to each other, but not equal to a quarter of the cycle. Despite this, each of the periods was normalized to one quarter of the cycle in the further analysis. The swing of left or right limb (periods 1 and 3 ) are shaded light gray, and the remaining periods ( 2 and 4 ) are shaded dark gray.

trode track gliosis. The positions of recording tracks in the motor cortex were estimated in relation to the reference lesions (Fig. $2 D-G$ ).

\section{Results}

\section{Kinematics and EMG patterns in different locomotor tasks}

Kinematics

Figure $3 A-E$ gives an example of walking kinematics in different tests. The general pattern of quadrupedal walking (Test $2 \mathrm{~F} 2 \mathrm{H}$ ) observed in the present study was similar to that described in a number of previous studies (e.g., Rasmussen et al., 1978). As shown in Figure $3 A$, all limbs were stepping (see traces of the AP foot position), with a phase shift of half of a cycle between the two limbs of each girdle, and with a phase shift of approximately one quarter of a cycle between the ipsilateral forelimb and hindlimb. In other tests, the cycle duration and the phase coordination between the stepping limbs was very similar (Fig. 3B-E).

The average cycle duration was about $1 \mathrm{~s}$ across all tasks except Test $2 \mathrm{H}$, during which the cycle was slightly longer (Fig. $3 F$ ). The average phase shift between the right and left limbs was about half a cycle in tests $2 \mathrm{~F} 2 \mathrm{H}, 2 \mathrm{~F}$, and $2 \mathrm{H}$ (Fig. $3 G$ ). The structure of the cycle (a relative duration of the periods 1-4) was similar across different tests, although, as can be seen in Figure $3 A-E$, the peri- 
ods varied slightly from cycle to cycle within the same episode of locomotion.

For a detailed analysis of kinematics patterns during different tests, we used Visualeyez System (see Materials and Methods), which recorded limb position at sequential points of the step cycle, and calculated joint angles at these points. Figure 4 shows representative stick diagrams of the right hindlimb $(A)$ and the right forelimb $(B)$ obtained in different tests, separately for the swing and stance phases of the step. The stick diagrams for walking limbs, regardless of test, were similar to those in the control test $(2 \mathrm{~F} 2 \mathrm{H})$. In those tests in which a limb was standing, its movements were very small.

Figure 5 shows averaged angular movements in the main joints of the right forelimb $(A)$ and of the right hindlimb $(B)$ of one cat during different tests. To characterize similarity of the angle profiles in a given bipedal test and in the quadrupedal test $(2 \mathrm{~F} 2 \mathrm{H})$, we calculated the $\mathrm{CC}$ between the two functions (see Materials and Methods). In the example shown in Figure 5, the CC values are indicated in each panel. We found that, in all analyzed cases (three cats, each recorded on 3 different days) when a limb was walking, CC was as high as 1.00 and not lower than 0.70 , thus indicating that the joint angle trajectory of the limb (walking in bipedal tests) was similar to that in control. By contrast, the kinematics of the standing limbs was completely different from that in control because of the absence of anterior-posterior movements (CC was $<0.5$ in all analyzed cases).

\section{EMG patterns}

Figure 6 shows averaged EMG patterns in the right forelimb and hindlimb observed in one cat during different tests. In Test $2 \mathrm{~F} 2 \mathrm{H}$, all EMGs were profoundly modulated. The flexors (Bra-R and Tib-R) were active in the swing phase of the step (period 1), and the extensors (Tric-R and Gast-R) were active during the stance phase (periods 2-4). This pattern was similar to that described in a number of previous studies [e.g., Krouchev et al. (2006), Rasmussen et al. (1978), and Trank et al. (1996)].

The EMG patterns observed in the other tests depended on the limb function. If a limb was involved in locomotion and performed stepping movements, the activity pattern of its muscles was similar to that of quadrupedal walking. Compare, for example, activity of Bra- $\mathrm{R}$ in Test $2 \mathrm{~F}$ and Test $2 \mathrm{R}$ with that in Test $2 \mathrm{~F} 2 \mathrm{H}$, or activity of Gast- $\mathrm{R}$ in Test $2 \mathrm{H}$ and Test $2 \mathrm{R}$ with that in Test $2 \mathrm{~F} 2 \mathrm{H}$. The most significant difference was observed in the activity of Tric- $\mathrm{R}$ in Test $2 \mathrm{R}$ (walking of two right limbs): during stance (phases $2-4$ ), this activity was $\sim 2$ times lower than in Test $2 \mathrm{~F} 2 \mathrm{H}$, which can be explained by unloading of the right limb due to continuous support of the body by the standing left limb. The variability in EMGs was small in all tasks.

To characterize similarity of EMG profiles in a given bipedal test and in the quadrupedal test $(2 \mathrm{~F} 2 \mathrm{H})$, we calculated the CC between the two curves (see Materials and Methods). The CC values are indicated in each panel of Figure 6 . For all cases when a limb was walking, the modulation pattern of its muscles was similar to that in control. The CC was as high as 0.98 and not lower than 0.72. The same was true for other cases in all cats, when we compared EMG patterns during bipedal walking: the $\mathrm{CC}$ for a muscle involved in walking was in the range from 0.70 to 1 (most often in the range from 0.9 to 1 ).

If a limb was standing, the muscle activity in this limb in most cases was tonic (see, e.g., Fig. 6, Bra-R in Test $2 \mathrm{H}$ and Test 2L; Tib-R in Test $2 \mathrm{~F}$ and Test $2 \mathrm{~L}$ ). If some step-related modulation persisted, it was weaker and/or had substantially different phasing as compared to control (e.g., Fig. 6, Gast-R in Test 2F and Test $2 \mathrm{~L})$. The CC calculated for these cases varied from -0.60 to 0.49 (Fig. 6). The same poor similarity was always observed for the EMGs in a standing limb: the CC was in the range from -0.8 to 0.5 (most often in the range from -0.2 to 0.2 , which could be expected since the EMG modulation typically disappeared in the standing limb).

To conclude, the kinematical and EMG data demonstrated that during bipedal locomotion, the activity of controllers in standing limbs was either absent or very different from their activity during quadrupedal locomotion. Thus, the somatosensory information as well as the efference copy signals from these controllers could not produce modulation patterns of motor cortical neurons similar to those during normal locomotion. On the other hand, during bipedal locomotion, kinematics and EMGs in the walking limb were similar to normal. Thus, signals from these controllers could produce close to normal modulation pattern in the motor cortex neurons.

\section{General characteristics of neuronal activity in different locomotor tasks}

Altogether, 155 neurons were recorded from the left motor cortex in three cats, including 84 forelimb-related neurons and 71 hindlimb-related neurons. Of these, 74 forelimb-related neurons and 64 hindlimb-related neurons were modulated in the control test $(2 \mathrm{~F} 2 \mathrm{H})$. Only these neurons were used for further analysis. Forelimb-related neurons most often responded to movements in the shoulder joint, fewer were activated by the wrist or toes movements, and several responded to movements in the elbow. 
A
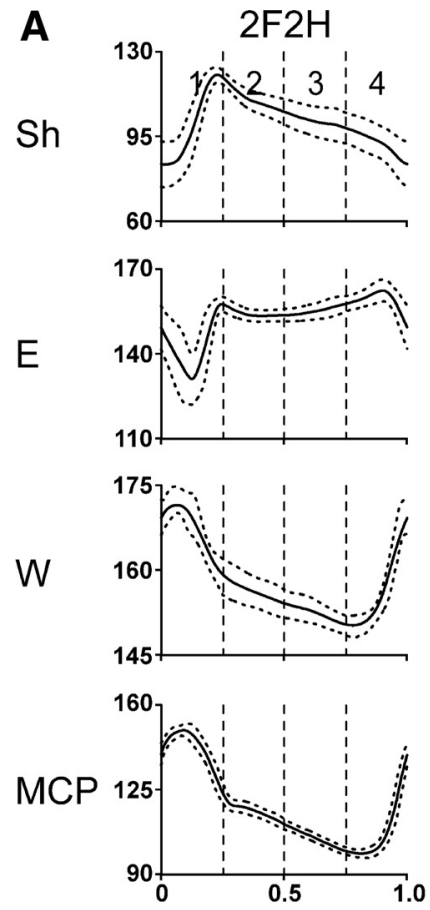

B
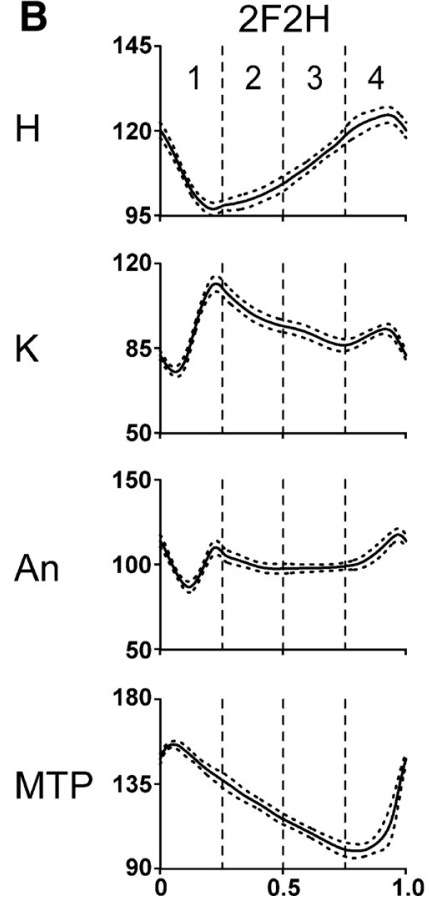

$2 \mathrm{~F}$
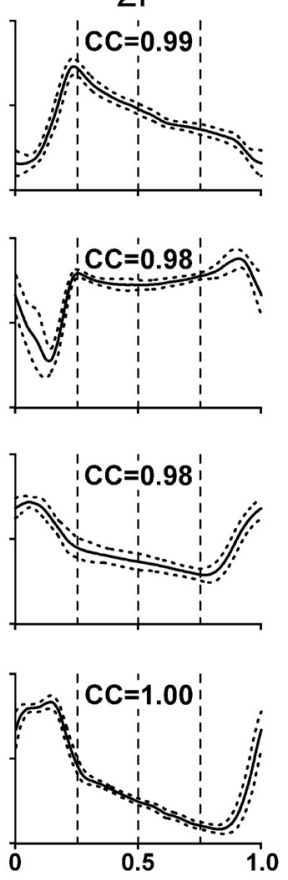

$2 \mathrm{H}$
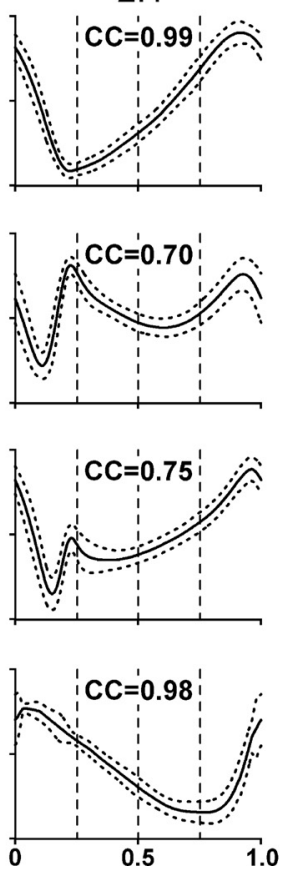

$2 R$
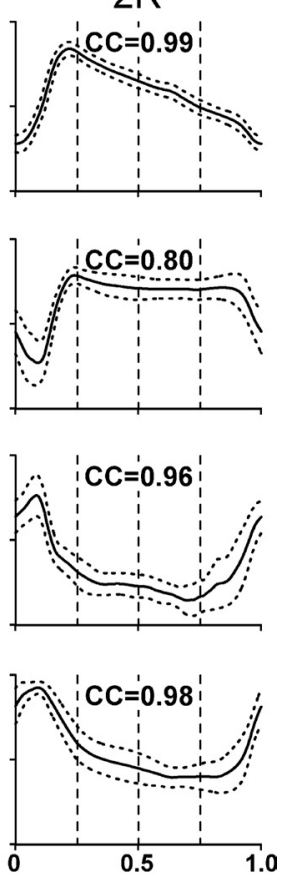

$2 \mathrm{R}$


Figure 5. Joint angle patterns in different tests. Averaged joint angles in different tests for four joints of the forelimb $(\boldsymbol{A})$ and the hindlimb (B) in one cat. H, Hip; K, knee; An, ankle; MTP, metatarsophalangeal; Sh, shoulder; E, elbow; W, wrist; $M C P$, metacarpophalangeal joints. Phase histograms were obtained for each of the periods (1-4) of the normalized locomotor cycle separately. Averaging was performed for 15-30 step cycles in each test; SD is shown by interrupted line. Ordinate, Degrees. The $\mathrm{CCs}$ of the joint angle pattern in a given bipedal test to the pattern in the control Test $2 \mathrm{~F} 2 \mathrm{H}$ are indicated.

In the hindlimb-related group, neurons were most often activated by movements in the hip or ankle joint; and many others responded to movements of toes or tapping on the sole. Receptive fields of several neurons included knee or encompassed the entire hindlimb. The majority of both forelimb-related and hindlimbrelated neurons $(65 \%$ and $60 \%$, respectively) were identified as PTNs. The following characteristics of neuronal activity were calculated in each of the locomotor tests:

\section{Mean frequency}

Figure 7, $A-D$ and $F-I$, plots the mean frequency $f_{\mathrm{M}}$ in different bipedal locomotor tests versus the mean frequency in the control test $(2 \mathrm{~F} 2 \mathrm{H})$ for the forelimb and hindlimb area neurons, respectively. The data points are concentrated along the diagonal, indicating that $f_{\mathrm{M}}$ did not depend on the form of locomotion. Correspondingly, no significant difference from the control was found for the population mean of $f_{\mathrm{M}}$ calculated for the forelimb (Fig. 7E) and hindlimb (Fig. 7J) area neurons. These findings show that none of the bipedal modes of locomotion required general activation of the motor cortex.

\section{Coefficient of modulation}

The majority of neurons that were modulated during the control test $(2 \mathrm{~F} 2 \mathrm{H})$ were also modulated during all other tests. However, the percentage of modulated neurons and the depth of their modulation differed in different tests. Figure 8, $A-D$ and $F-I$, plots the coefficient of modulation $K_{\text {mod }}$ in different bipedal locomotor tests versus the coefficient of modulation in the control test, for the forelimb and hindlimb populations of neurons, respectively ( $K_{\bmod }$ of nonmodulated neurons is set equal to 0$)$. The data points are scattered over the plot, indicating that the depth of modulation could change differently in different neurons. There was, however, a clear tendency for $K_{\text {mod }}$ to be smaller in those bipedal tests, in which the corresponding contralateral limb was standing (Fig. $8 B, D, F, I$ ) as compared to Test $2 \mathrm{~F} 2 \mathrm{H}$. The value of $K_{\text {mod }}$ was on average smaller during these tests (Fig. $8 E$, J, light gray columns), as compared to Test 2F2H (black columns). By contrast, $K_{\text {mod }}$ was close to control in those bipedal tests in which the limb was walking (dark gray columns).

These findings suggest that the influences from the corresponding contralateral limb represent one, but not the only, source for modulation of neuronal activity in the motor cortex. They also show that, during bipedal walking, there is no general increase in the depth of modulation of motor cortex neurons.

\section{Preferred phase}

During quadrupedal locomotion, the preferred phases of different neurons were almost evenly distributed over the step cycle, as shown in Figure 9 for the forelimb $(A)$ and hindlimb $(B)$ area populations of neurons. During bipedal locomotion, if modulation did not disappear, the preferred phases could change. Figure $9 C-J$ shows the histograms of the difference in the preferred phase between the bipedal and the quadrupedal $(2 \mathrm{~F} 2 \mathrm{H})$ locomotion tests. For most neurons, shift of 

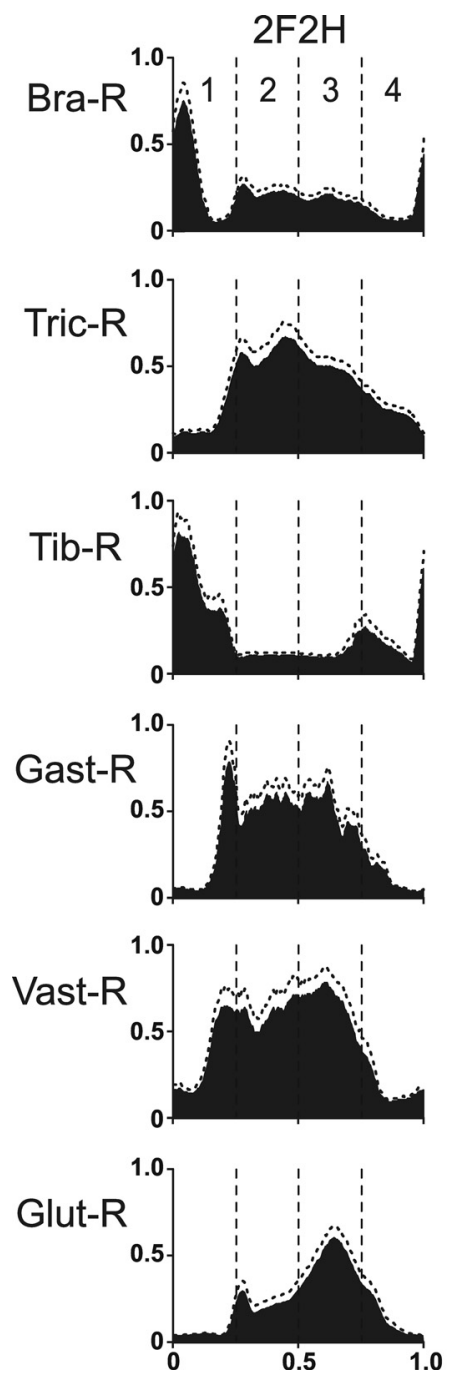

$2 \mathrm{~F}$
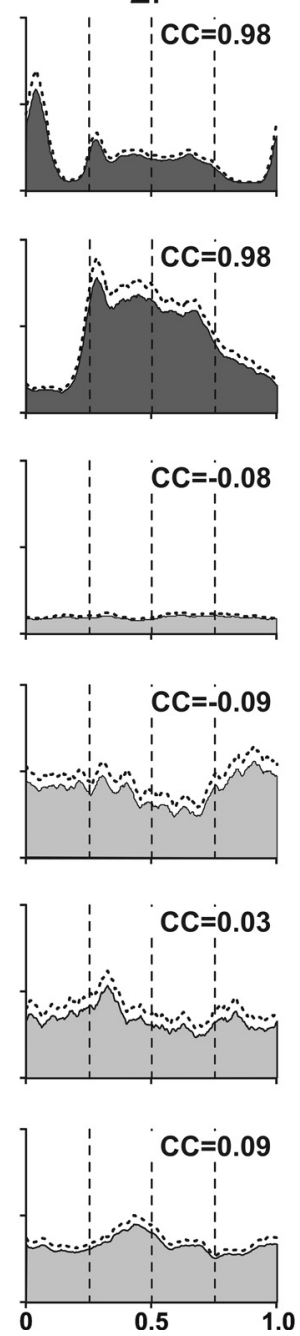

$2 \mathrm{H}$


$2 \mathrm{R}$
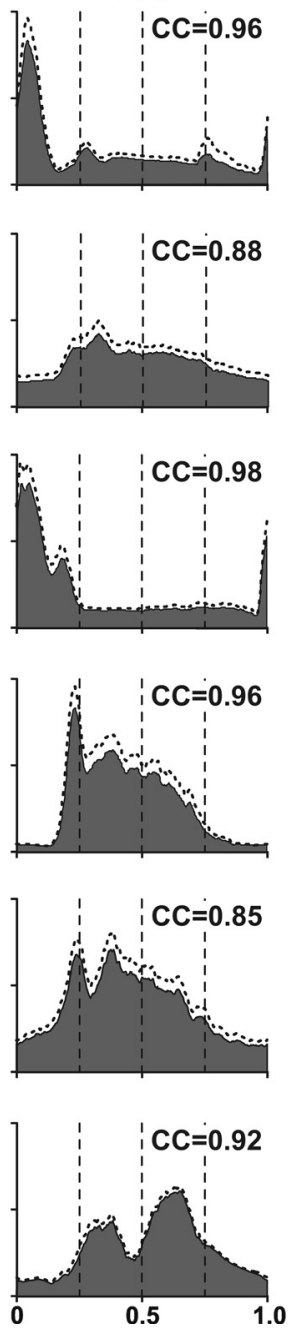

$2 \mathrm{~L}$
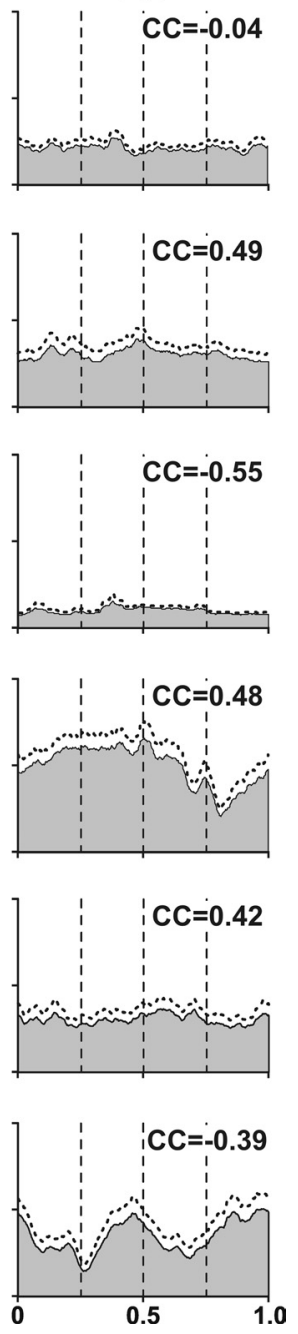

Figure 6. EMG patterns in different locomotor tasks. Averaged EMGs in different tests for six muscles: Bra-R, Tric-R, Tib-R, Gast-R, Vast-R, and Glut-R. Phase histograms were obtained for each of the periods (1-4) of the normalized locomotor cycle in one cat. Averaging was performed for 15-30 locomotor cycles in each test. SD is indicated by interrupted line. Ordinate, Arbitrary units (the same for all tests). The histograms for the control quadrupedal locomotion are colored black, for the bipedal tests in which a limb containing the muscle was walking are colored dark gray, and those for the bipedal tests in which the limb was standing are colored light gray. The CCs of the EMG pattern in a given bipedal test to the pattern in the control test are indicated.

the preferred phase was very small (in the range of $\pm 10 \%$ of the step cycle) in those tests in which the contralateral limb corresponding to the neuron was walking (Fig. 9C, E, H,I). By contrast, the shift was much larger in those tests in which that limb was standing (Fig. 9D, F,G,J). The distribution of shifts in these tests was flat ( $\chi^{2}$ test, $\left.p>0.05\right)$. These findings suggest that, when the corresponding contralateral limb is not walking and the normal phasic influences from this limb are absent, the modulation pattern in the majority of motor cortex neurons is different from the one observed during quadrupedal walk.

\section{Comparison of modulation patterns of neurons in different locomotor tasks}

The observed changes in the general characteristics of modulation (coefficient of modulation, preferred phase) in different tests (Figs. 8,9 ) suggested that modulation of motor cortex neurons was often determined by signals coming not only from the corresponding contralateral limb but also from the other limbs. To reveal the contribution of different limbs, a correlation analysis of the patterns of modulation during different tests was performed for individual neurons.
Before we present results of this analysis, we want to articulate the following considerations. As shown above (Figs. 3-6), movement kinematics and EMG patterns during bipedal walking were largely similar to those in the control test $(2 \mathrm{~F} 2 \mathrm{H})$ for the limbs that were walking, suggesting that the locomotor limb controller operates similarly in these tests. By contrast, movement kinematics and EMG patterns were highly different from the control test for the limbs that were standing. Based on these data, we assumed the following: (1) If the only source of modulation of a neuron is the controller of its corresponding contralateral limb, the modulation pattern will be similar to the control in all bipedal tests in which this limb is walking, and dissimilar in all bipedal tests in which it is standing. (2) If modulating signals come from several limb controllers and signals from each one are sufficient for modulation, then exclusion of the corresponding contralateral limb from locomotion will not influence the modulation pattern. (3) If, however, signals from all limb controllers are necessary for normal modulation, exclusion of any limb from locomotion will change the modulation pattern. To choose between these options, we compared the modulation patterns (phase histograms) of individual neurons in each bipedal test with the modulation 

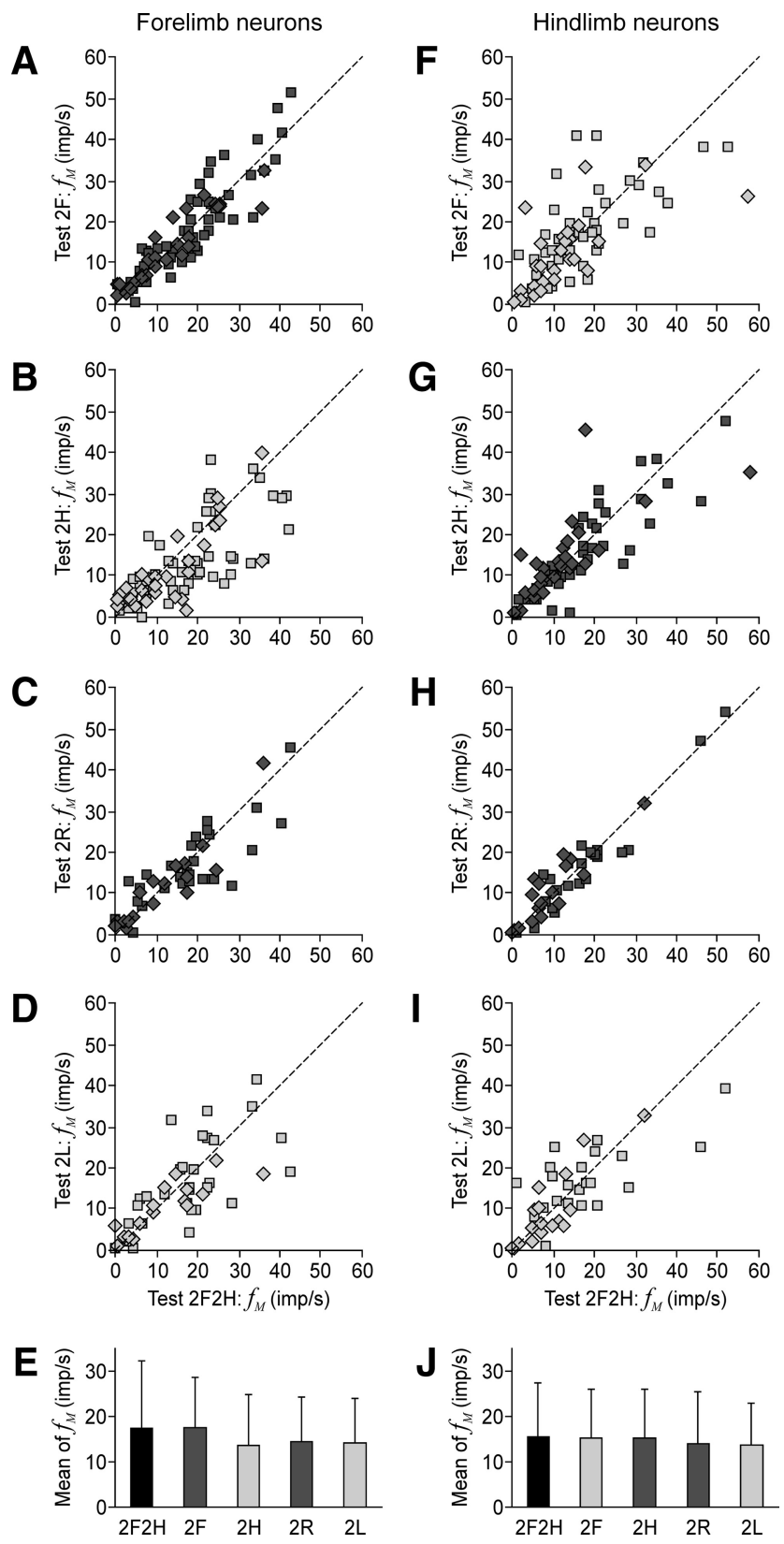

Figure 7. Mean discharge frequency of neurons in different locomotor tasks. $A-D, F-I$, The scatter plots for the mean frequency $f_{M}$ in different bipedal walking tests plotted against the control Test $2 \mathrm{~F} 2 \mathrm{H}$, for the forelimb and hindlimb neurons, correspondingly. Squares indicate the data points for PTNs, and diamonds indicate those for nonidentified neurons. $\boldsymbol{E}$, J, The population average ( $\pm S D$ ) of the mean frequency (mean of $f_{M}$ ) in different tests, for the forelimb population of neurons $(\boldsymbol{E})$ and for the hindlimb population $(\boldsymbol{J})$. The averages were calculated together for PTNs and nonidentified neurons. The columns for the control test are colored black. The dots and columns for the tests in which the own limb was walking are colored dark gray. The dots and columns for the tests in which the own limb was standing are colored light gray. The numbers of forelimb neurons in different tests are as follows: $n=74(2 \mathrm{~F} 2 \mathrm{H}), n=74(2 \mathrm{~F}), n=$ $74(2 \mathrm{H}), n=47(2 \mathrm{R})$, and $n=47(2 \mathrm{~L})$. The numbers of hindlimb neurons in different tests are as follows: $n=64(2 \mathrm{~F} 2 \mathrm{H}), n=64(2 \mathrm{~F}), n=64(2 \mathrm{H}), n=39(2 \mathrm{R})$, and $n=39$ (2L).

pattern in Test $2 \mathrm{~F} 2 \mathrm{H}$, and calculated the CC (see Materials and Methods).

Six examples of neuronal discharges during pairs of locomotion tests, with the results of cross-correlation analysis indicated, are presented in Figure 10. They are shown in the order of decreasing similarity of the modulation pattern in a bipedal task with that in control. Thus, Figure $10 \mathrm{~A}$ shows a hindlimb area
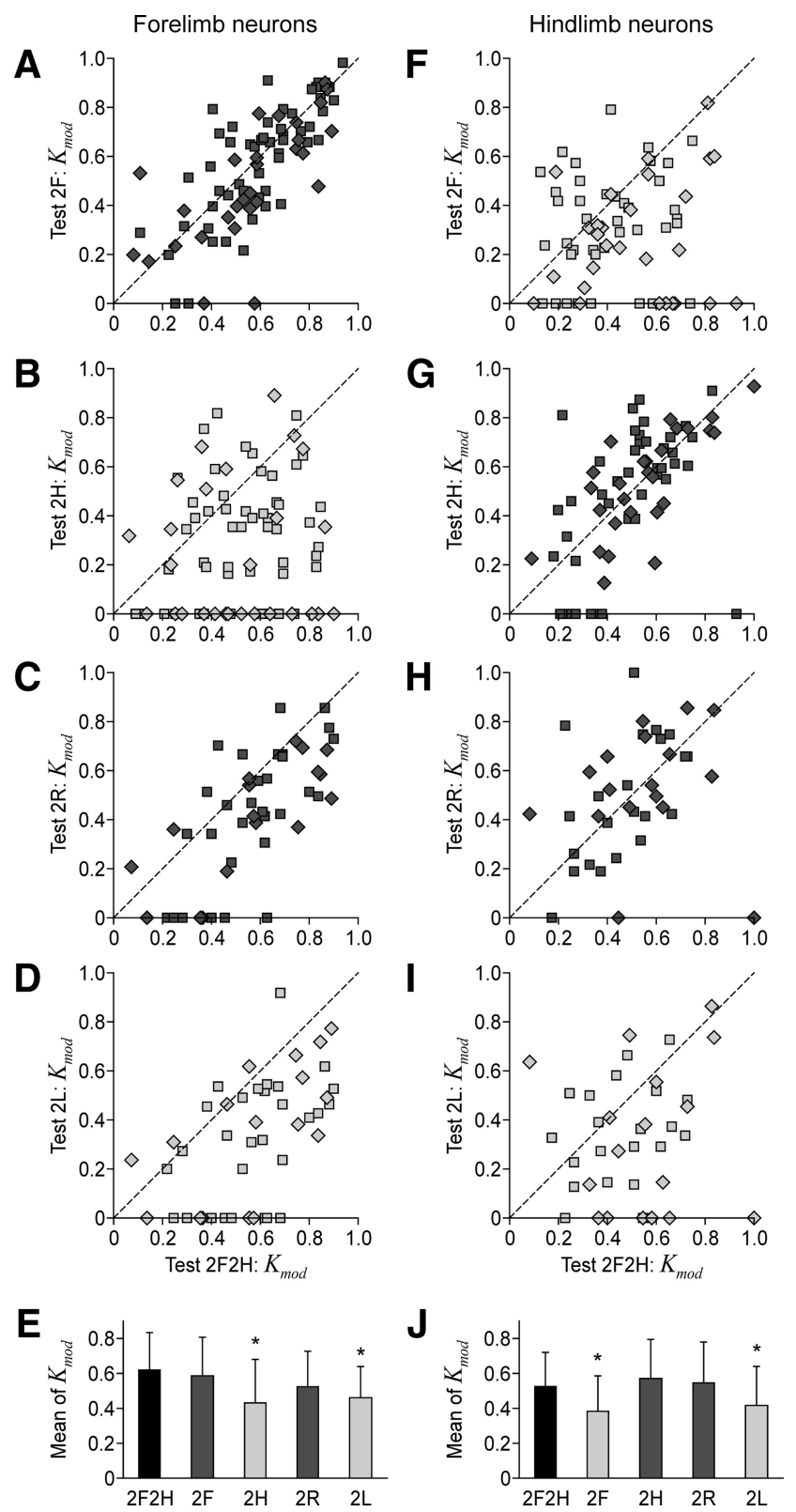

Figure 8. Coefficient of frequency modulation of neurons in different locomotor tasks. $A-D$, $\boldsymbol{F}-\boldsymbol{I}$, The scatter plots for the coefficient of modulation $K_{\text {mod }}$ in different bipedal walking tests plotted against the control Test $2 \mathrm{~F} 2 \mathrm{H}$, for the forelimb and hindlimb neurons, correspondingly. $\boldsymbol{E}, \boldsymbol{J}$, The population average ( $\pm S D$ ) of the coefficient of modulation (mean of $K_{\text {mod }}$ ) in different tests, for the forelimb population of neurons $(\boldsymbol{E})$ and for the hindlimb population $(\boldsymbol{J})$. Asterisks indicate a statistically significant change of the population average relative to Test $2 \mathrm{~F} 2 \mathrm{H}$. Other designations and the number of neurons are as in Figure 7.

neuron, in which the pattern of modulation in Test $2 \mathrm{~L}$ was similar to that in Test $2 \mathrm{~F} 2 \mathrm{H}$, and CC was as large as 0.99 (albeit in this example, as in many others, the mean frequency of discharge in the two tests was quite different). Figure $10 \mathrm{~B}$ shows a forelimb area neuron, which was most active in the swing phase (period 1) both in Test $2 \mathrm{~F} 2 \mathrm{H}$ and in Test $2 \mathrm{R}$, while in the stance phase its activity patterns were different, which resulted in a smaller CC (0.76). Figure $10 \mathrm{C}$ shows a hindlimb area neuron, whose activity during both Test $2 \mathrm{~F} 2 \mathrm{H}$ and Test $2 \mathrm{H}$ fell sharply at the end of the swing phase (period 1), and was high during the second half of the cycle (periods 3-4). Despite a great difference between the activity patterns in the second quarter of the cycle (period 2), CC was rather large (0.69). 


\section{Preferred phase in Test $2 \mathrm{~F} 2 \mathrm{H}$}

A

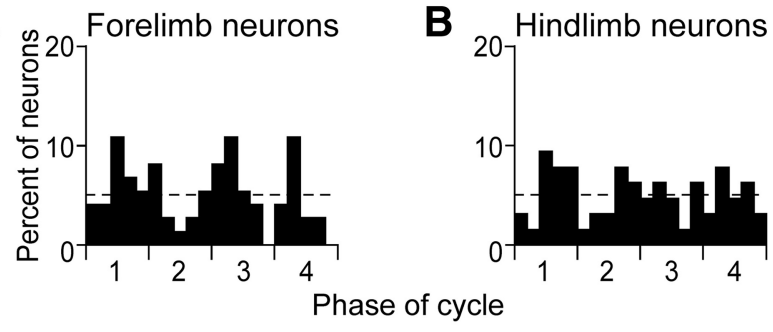

Change of preferred phase in relation to Test $2 \mathrm{~F} 2 \mathrm{H}$
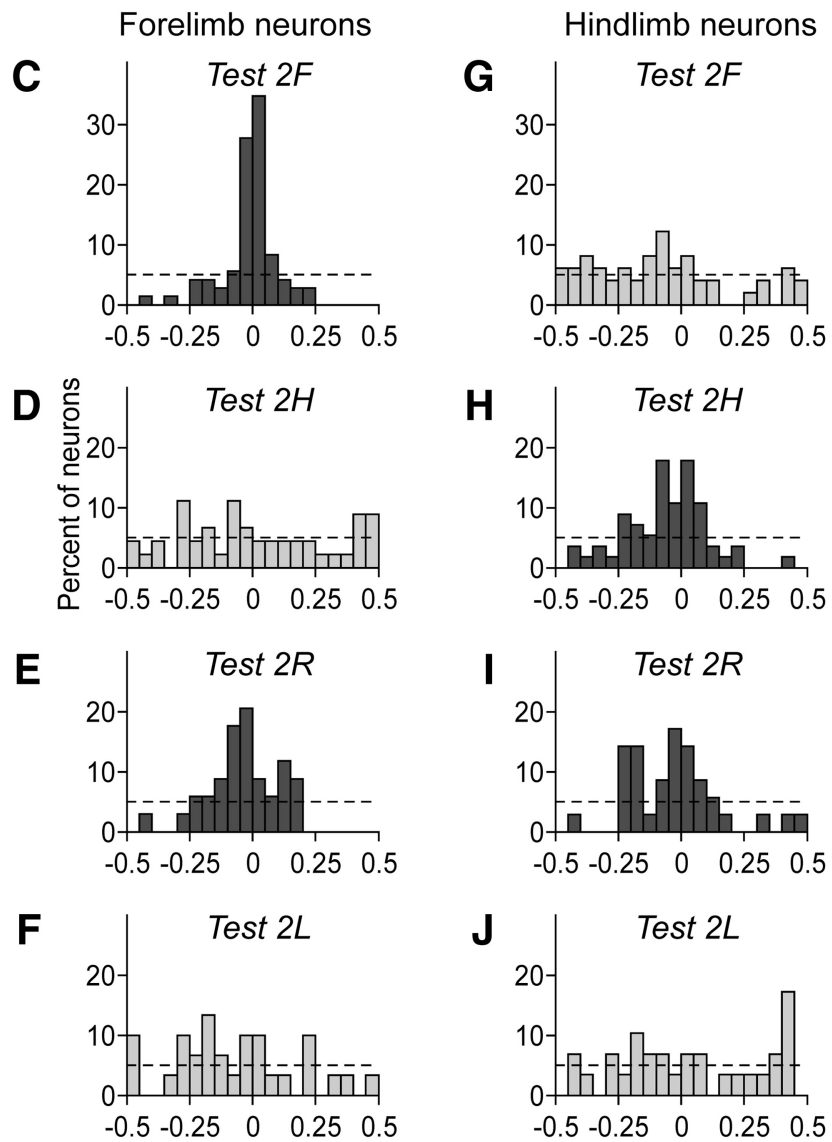

Change of phase

Figure 9. Changes of preferred phase of neurons in bipedal tasks relative to quadrupedal locomotion. The histograms in $\boldsymbol{A}$ and $\boldsymbol{B}$ show the distribution of preferred phases of forelimb neurons $(\boldsymbol{A})$ and hindlimb neurons $(\boldsymbol{B})$ in the control test $(2 \mathrm{~F} 2 \mathrm{H})$. The four periods (1-4) of the normalized locomotor cycle are indicated (see Fig. 3). The hatched line indicates the level of random distribution of preferred phases. The histograms in $\mathbf{C} \boldsymbol{F}$ and $\mathbf{G} \boldsymbol{J}$ show the algebraic difference between the preferred phases of individual neurons in a given test and in the control test, for the forelimb and hindlimb neurons, respectively. Histogram columns for the control test are colored black, the columns for the tests in which the own (projection) limb was walking are colored dark gray, and the columns for the tests in which the own limb was standing are colored light gray. The hatched lines in $\boldsymbol{C} \boldsymbol{J}$ indicate the level of random distribution of the phase differences. The $\chi^{2}$ test showed that in the tests in which the own limb was standing $(\boldsymbol{D}, \boldsymbol{F}, \boldsymbol{G}, \boldsymbol{J})$, the distribution was random $(p>0.05)$.

Examples presented in Figure 10D-F show neurons whose activity during a bipedal test was even more different from that in control. The hindlimb area neuron shown in Figure $10 \mathrm{D}$ was active in the swing phase during both Test $2 \mathrm{~F} 2 \mathrm{H}$ and Test $2 \mathrm{R}$. However, the modulation patterns during both the swing and stance phases were very different, and CC was small (0.34). The activity of a hindlimb area neuron presented in Figure $10 \mathrm{~F}$ was modulated during both tests. However, the pattern in Test $2 \mathrm{~F} 2 \mathrm{H}$ differed strongly from that in Test $2 \mathrm{R}$, and CC was small and negative $(-0.34)$. Finally, Figure $10 E$ shows a forelimb area neuron, which was not modulated in Test $2 \mathrm{H}$, and CC was very small (0.17). In all cases when the activity was not modulated during a bipedal task, CC was within a range from -0.5 to +0.5 (most often within a range from -0.2 to +0.2 ).

We chose the CC values larger than +0.6 as indicative for similarity of the two modulation patterns (additional arguments for this choice that also take into consideration CC values of kinematics and muscle activity patters during different tasks are given in Discussion). Based on this criterion, the patterns shown in Figure $10 A-C$ were similar to the control, and those in Figure $10 D-F$ were dissimilar.

For all neurons tested, we determined the CC values for comparisons between different bipedal tests versus quadrupedal test. The results of analysis are summarized in Figure 11 for the forelimb area neurons $(A, B)$ and for the hindlimb area neurons $(C, D)$. In these scatter diagrams, one point represents one neuron; all neurons were recorded from the left motor cortex. In Figure $11 A$, we compared walking with different girdles for forelimb area neurons. In this diagram, the abscissa of each point is $\mathrm{CC}$ in the comparison $(2 \mathrm{~F}, 2 \mathrm{~F} 2 \mathrm{H})$, and the ordinate is $\mathrm{CC}$ in the comparison $(2 \mathrm{H}, 2 \mathrm{~F} 2 \mathrm{H})$. The $\mathrm{CC}$ varied within a wide range. The interrupted lines at $\mathrm{CC}=0.6$ divide the plot area into four parts ( 1 , 2,3 , and 4 ) and all neurons into four corresponding groups, G1-G4 (indicated by different colors in Fig. 11 A).

In group $\mathrm{G} 1$, the pattern of modulation in Test $2 \mathrm{~F} 2 \mathrm{H}$ was similar to that in Test $2 \mathrm{~F}$ (walking of the own girdle) but dissimilar from that in Test $2 \mathrm{H}$ (walking of the other girdle). In group G2, the pattern in Test $2 \mathrm{~F} 2 \mathrm{H}$ was similar to those in Test $2 \mathrm{~F}$ and Test $2 \mathrm{H}$, i.e., it was similar during walking of any girdle. In group G3, the pattern in Test $2 \mathrm{~F} 2 \mathrm{H}$ was dissimilar from those in Test $2 \mathrm{~F}$ and Test $2 \mathrm{H}$. Finally, no neurons were found in group G4, with the pattern in Test $2 \mathrm{~F} 2 \mathrm{H}$ dissimilar from that in Test $2 \mathrm{~F}$ (walking of the own girdle) but similar to that in Test $2 \mathrm{H}$ (walking of the other girdle).

In Figure $11 B$, we compared walking with the right limbs to walking with the left limbs for the same forelimb area neurons that were shown in Figure $11 \mathrm{~A}$. Here the abscissa of each point is $\mathrm{CC}$ in the comparison $(2 \mathrm{R}, 2 \mathrm{~F} 2 \mathrm{H})$, and the ordinate is $\mathrm{CC}$ in the comparison $(2 \mathrm{~L}, 2 \mathrm{~F} 2 \mathrm{H})$. To keep track of neurons from the groups shown in Figure $11 A$, they are indicated by the same colors. As in Figure $11 A$, the lines $\mathrm{CC}=0.6$ divide the plot area into four parts $(1,2,3$, and 4$)$ and the neurons of each group G1-G3 (as defined in Fig. 11A) into the corresponding subgroups (G1-1, G1-2, etc.).

Table 1 summarizes the results of these comparisons for forelimb area neurons. It shows the number of neurons in each subgroup. For each subgroup, the tests with $\mathrm{CC}>0.6$ are indicated, as well as the corresponding primary sources of the step-related modulation in the control test $(2 \mathrm{~F} 2 \mathrm{H})$.

Subgroup G1-1 had CC $>0.6$ in the comparisons $(2 \mathrm{~F}, 2 \mathrm{~F} 2 \mathrm{H})$ and $(2 \mathrm{R}, 2 \mathrm{~F} 2 \mathrm{H})$. Since the only limb walking in both tests was the right forelimb, the controller of this limb was the only source of modulation in these neurons.

Subgroup G1-2 had CC $>0.6$ in the comparisons $(2 \mathrm{~F}, 2 \mathrm{~F} 2 \mathrm{H})$, $(2 \mathrm{R}, 2 \mathrm{~F} 2 \mathrm{H})$, and $(2 \mathrm{~L}, 2 \mathrm{~F} 2 \mathrm{H})$, but not in $(2 \mathrm{H}, 2 \mathrm{~F} 2 \mathrm{H})$, suggesting that input from either of the forelimbs was sufficient for driving these neurons. 

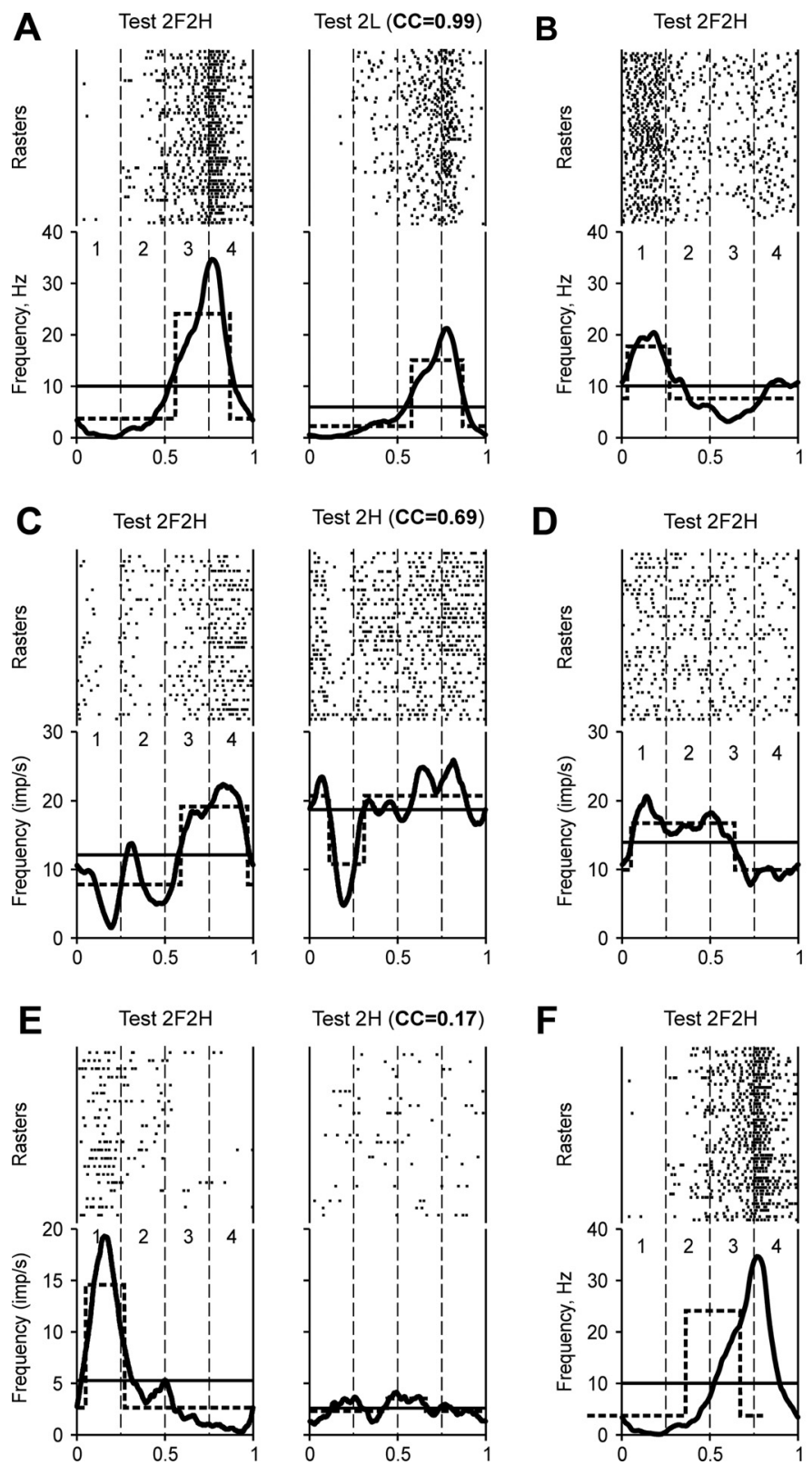

Figure 10. Comparison of modulation patterns of individual neurons during different locomotor tasks. For each test, the raster and the histogram (thick line) of the neuron activity are shown. Cycle periods (1-4) were taken from hindlimb movements $(\boldsymbol{A}, \boldsymbol{C}$, $\boldsymbol{D}, \boldsymbol{F})$ and forelimb movements $(\boldsymbol{B}, \boldsymbol{E})$. The hatched lines show the best two-level rectangular approximations of the histograms, with the burst period (upper level) and interburst period (lower level). The thin lines give the mean spiking frequency in a test. The test type and the $\mathrm{CC}$ between the phase histograms obtained in the test and in Test $2 \mathrm{~F} 2 \mathrm{H}$ (control) are indicated. The examples are taken from five neurons (the same neuron in $\boldsymbol{A}$ and $\boldsymbol{F})$. They were classified (see Figs. 11, 12) as 1-4 $(\boldsymbol{A}$, $\boldsymbol{F}), 1-1(\boldsymbol{B}), 1-3(\boldsymbol{C}, \boldsymbol{D})$, and 1-2 (E).

Subgroup G1-3 had CC $>0.6$ only in the comparison $(2 \mathrm{~F}$, $2 \mathrm{~F} 2 \mathrm{H})$, suggesting that modulation of these neurons required inputs from the controllers of both forelimbs.

Subgroup G1-4 had CC $>0.6$ in the comparisons $(2 \mathrm{~F}, 2 \mathrm{~F} 2 \mathrm{H})$ and $(2 \mathrm{~L}, 2 \mathrm{~F} 2 \mathrm{H})$. The only limb walking in both tests was the left forelimb. Therefore, the controller of this limb was the only source of modulation in these neurons.

Subgroup G2-1 had CC $>0.6$ in the comparisons $(2 \mathrm{~F}, 2 \mathrm{~F} 2 \mathrm{H})$, $(2 \mathrm{H}, 2 \mathrm{~F} 2 \mathrm{H})$, and $(2 \mathrm{R}, 2 \mathrm{~F} 2 \mathrm{H})$, but not in $(2 \mathrm{~L}, 2 \mathrm{~F} 2 \mathrm{H})$, suggesting that input from either of the right limbs was sufficient for driving these neurons.
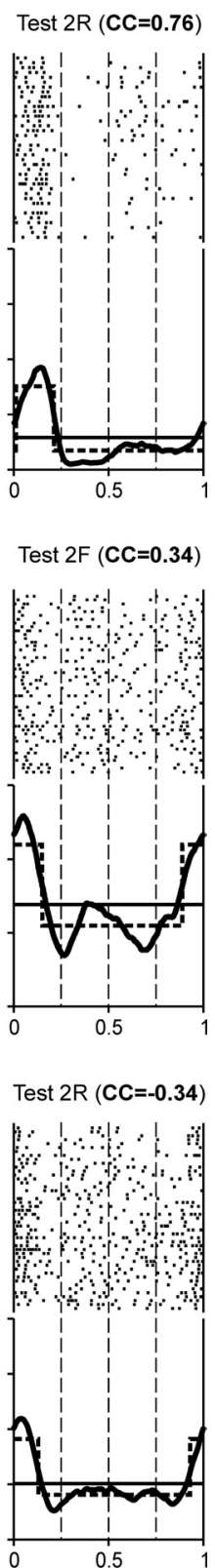

Subgroup G2-3 had CC $>0.6$ in the comparisons $(2 \mathrm{~F}, 2 \mathrm{~F} 2 \mathrm{H})$ and $(2 \mathrm{H}, 2 \mathrm{~F} 2 \mathrm{H})$, suggesting that input from the controllers of each girdle was sufficient for driving these neurons.

Subgroup G3-1 had CC $>0.6$ only in the comparison $(2 \mathrm{R}, 2 \mathrm{~F} 2 \mathrm{H})$, suggesting that inputs from the controllers of both right limbs were necessary for normal modulation of these neurons.

Subgroup G3-2 had CC $>0.6$ in the comparisons $(2 \mathrm{R}, 2 \mathrm{~F} 2 \mathrm{H})$ and $(2 \mathrm{~L}, 2 \mathrm{~F} 2 \mathrm{H})$. It seems most likely that input from the controllers of each side was sufficient for driving these neurons.

Subgroup G3-3 had CC $>0.6$ in none of the comparisons, suggesting that inputs from all limb controllers were necessary for normal modulation of these neurons in the control test $(2 \mathrm{~F} 2 \mathrm{H})$.

A similar analysis was performed for the hindlimb area neurons. Its results are presented in Figure 11, $C$ and $D$, and summarized in Table 2. As one can see from the tables, in total there were nine subgroups of forelimb area neurons and eight subgroups of hindlimb area neurons. The subgroups differed in the combination of inputs from different limb controllers and in the relative contribution of these inputs to the periodic modulation of neurons.

Modulation patterns of neurons from subgroup G1-2 were similar to the control (Test 2F2H) if any (right or left) limb of the own girdle was involved in walking (apparently inputs came at the same phase of locomotion). Modulation patterns of neurons from subgroup G1-3 are similar to the control only if both limbs of the own girdle were involved in walking; inputs from the two limbs could have come in different phases of locomotor cycle. Thus, although the patterns of influences from the two limbs were different, neurons of both subgroups received inputs from both limbs of the own girdle. That is why we united these subgroups into one functional group, F2 for the forelimb area neurons and $\mathrm{H} 2$ for the hindlimb area neurons.

In a similar fashion, we united the subgroups of neurons receiving inputs from identical combinations of limb controllers (regardless to their relative contribution) into the functional groups (Fig. 12). In total, there were five functional groups of forelimb area neurons (F1-F5 in Fig. 12A) and five groups of hindlimb area neurons (H1-H5 in Fig. 12B). In each of these groups, the contribution of different subgroups of neurons (termed as in Tables 1 and 2) is indicated by dividing the bar into the corresponding parts. Figure 12 also shows the proportion of antidromically activated neurons in each neuronal group (thick vertical lines). PTNs constituted $65 \%$ of recorded forelimb area 
neurons and $60 \%$ of recorded hindlimb area neurons) are proportionally presented in each of the groups.

\section{Discussion}

The objective of this study was to determine the origin of periodic, step-related frequency modulation observed during locomotion in motor cortex neurons [see, e.g., Armstrong and Drew (1984), Beloozerova and Sirota (1985, 1993a,b), Drew (1993), and Widajewicz et al. (1994)]. The motor cortex does not contribute to generation of simple locomotion because its fast inactivation does not affect this behavior (Beloozerova and Sirota, 1993a,b). On the other hand, it is well established that stepping movements of each limb, at least in simple environmental conditions, are generated by a separate mechanism (limb controller) located in the spinal cord [e.g., Shik and Orlovsky (1976), Arshavsky et al. (1986), Rossignol (1996), Drew et al. (1996), and Orlovsky et al. (1999)]. Therefore, the specific aim of this study was to assess the contribution of each of these mechanisms to the periodic modulation of motor cortex neurons during locomotion.

The method used in the present study allowed us to exclude different pairs of limbs from participation in locomotion as the cat walked on the treadmill (Fig. 1), and to assess neuronal discharges under these various conditions. The kinematics and EMG patterns in the walking limbs during bipedal locomotion were largely similar to those during normal quadrupedal locomotion (Figs. 3-6). By contrast, in the standing limbs, there was a considerable reduction or complete cessation of the periodic modulation of EMGs. Instances of small residual modulation could be due to the central influences from the stepping limbs, or due to the reflex reactions of the standing limb to its loading/unloading caused mechanically by the stepping limbs. It was found that, in such cases, the EMG patterns had no similarity to the normal ones (Fig. 6).

While quadrupedal walking in the cat under simple environmental conditions is largely based on the activity of limb controllers and does not require cortical participation (for review, see Drew et al., 1996), one may hypothesize that bipedal walking requires an enhanced cortical control. In this study, however, we did not observe any general activation of the motor cortex or an increase in the modulation depth of neuronal activity during any of the bipedal locomotion tasks tested. Instead, in the tests, in which the contralateral limb corresponding to a neuron was standing, we observed a decrease in the neuron's activity modulation, or a complete disappearance of modulation (Figs. 7, 8). Thus it appears that none of the well practiced forms of bipedal locomotion requires augmented participation of the motor cortex. In addition, the variability in EMGs was very similar across all tasks tested, suggesting a similar level of automatism for all of them. Therefore, we assume that the modulation of motor cortex
Forelimb neurons $(n=40)$
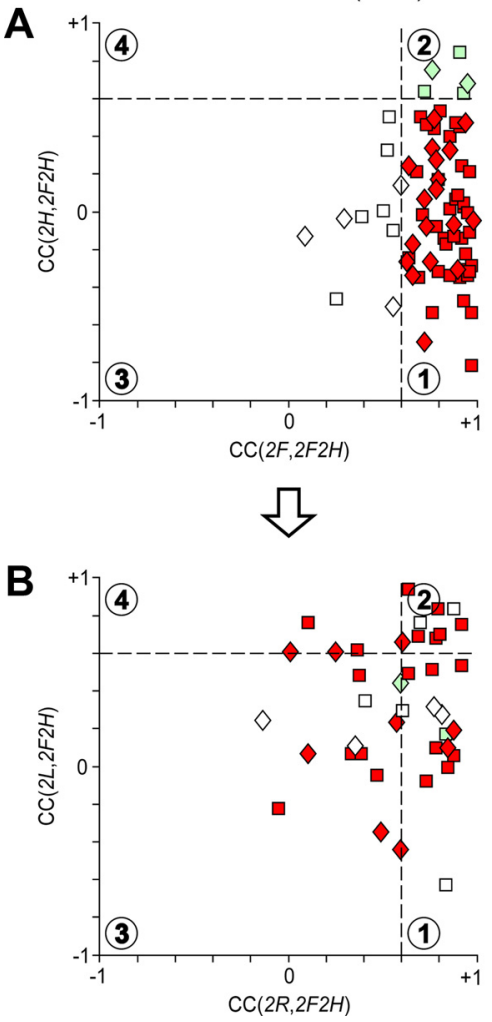

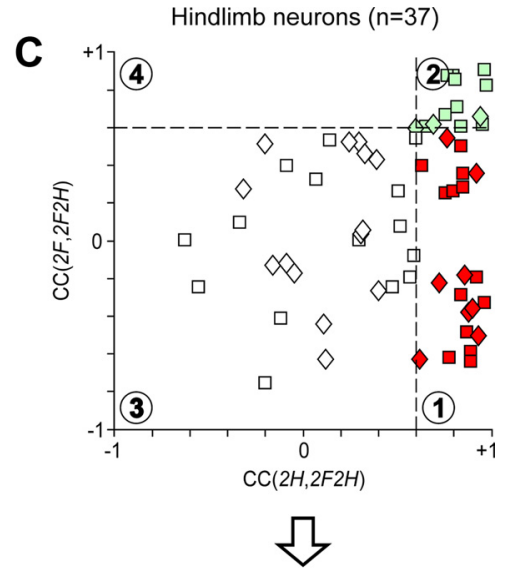

D

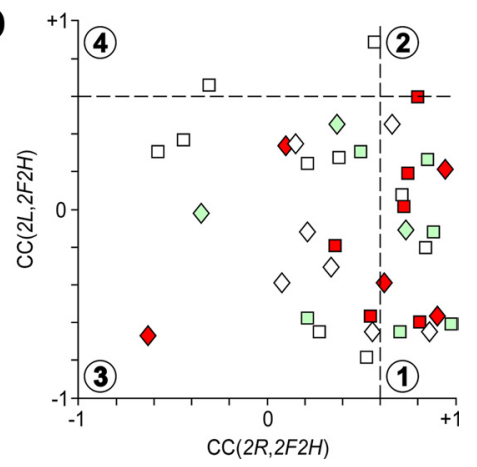

Figure 11. Similarities and distinctions in modulation patterns of neurons in different locomotor tasks. In the scatter diagrams, the $x$ and $y$ values of each point show the $C($ for individual forelimb neurons $(\boldsymbol{A}, \boldsymbol{B})$ and hindlimb neurons $(\boldsymbol{C}, \boldsymbol{D})$. and ordinate is the $\mathrm{CC}$ of tests $(2 \mathrm{~L}, 2 \mathrm{~F} 2 \mathrm{H})$. $\mathrm{C}$, Abscissa is the $\mathrm{CC}$ of tests $(2 \mathrm{H}, 2 \mathrm{~F} 2 \mathrm{H})$, and ordinate is the CC of tests $(2 \mathrm{~F}, 2 \mathrm{~F} 2 \mathrm{H})$. , Abscissa is the $\mathrm{CC}$ of tests $(2 \mathrm{R}, 2 \mathrm{~F} 2 \mathrm{H})$, and ordinate is the $\mathrm{CC}$ of tests $(2 \mathrm{~L}, 2 \mathrm{~F} 2 \mathrm{H})$. A similarity between the activity pattern was considered significant for $C(>0.6$. Two interrupted lines at $C C=0.6$ divide the whole plot area into four parts $(1-4$ with $C(>0.6$ in none of the tests (area 3). Green squares indicate the neurons with $C(>0.6$ in both tests (area 2). Red shown with squares; data for unidentified neurons are shown with diamonds. All revealed subgroups of neurons contained both PTNs and unidentified neurons.

Table 1. Classification of forelimb neurons $(n=40)$

\begin{tabular}{|c|c|c|c|c|}
\hline $\begin{array}{l}\text { Groups and } \\
\text { subgroups }\end{array}$ & $\begin{array}{l}\text { Number of } \\
\text { neurons }^{a}\end{array}$ & $\begin{array}{l}\text { Percent of } \\
\text { neurons }^{a}\end{array}$ & $\begin{array}{l}\text { Tests with } \mathrm{CC}>0.6 \\
\text { relative to } 2 \mathrm{~F} 2 \mathrm{H}\end{array}$ & $\begin{array}{l}\text { Sources of } \\
\text { modulation }^{b}\end{array}$ \\
\hline $1-1$ & $9(7)$ & $22.5(17.5)$ & $2 \mathrm{~F}, 2 \mathrm{R}$ & FR \\
\hline $1-2$ & $7(6)$ & $17.5(15.0)$ & $2 \mathrm{~F}, 2 \mathrm{R}, 2 \mathrm{~L}$ & $\mathrm{FR} / \mathrm{FL}$ \\
\hline $1-3$ & $9(5)$ & $22.5(12.5)$ & $2 \mathrm{~F}$ & $\mathrm{FR}+\mathrm{FL}$ \\
\hline $1-4$ & $4(2)$ & $10.0(5.0)$ & $2 \mathrm{~F}, 2 \mathrm{~L}$ & $\mathrm{FL}$ \\
\hline $2-1$ & $1(1)$ & $2.5(2.5)$ & $2 \mathrm{~F}, 2 \mathrm{H}, 2 \mathrm{R}$ & $\mathrm{FR} / \mathrm{HR}$ \\
\hline $2-3$ & $1(0)$ & $2.5(0.0)$ & $2 \mathrm{~F}, 2 \mathrm{H}$ & $\mathrm{FR}+\mathrm{FL} / \mathrm{HR}+\mathrm{HL}$ \\
\hline $3-1$ & $4(2)$ & $10.0(5.0)$ & $2 R$ & $F R+H R$ \\
\hline $3-2$ & $2(2)$ & $5.0(5.0)$ & $2 \mathrm{R}, 2 \mathrm{~L}$ & $\mathrm{FR}+\mathrm{HR} / \mathrm{FL}+\mathrm{HL}$ \\
\hline $3-3$ & $3(1)$ & $7.5(2.5)$ & 一 & $\mathrm{FR}+\mathrm{FL}+\mathrm{HR}+\mathrm{HL}$ \\
\hline
\end{tabular}

${ }^{a}$ Number or percentage of antidromically identified neurons is indicated in parentheses.

${ }^{b}$ Convergence of inputs necessary for generating the modulation pattern similar to that in control is indicated by a plus sign. Equivalence of inputs (or of their combinations) is indicated by a slash.

neurons during bipedal walking in our study was primarily determined by signals coming from the spinal limb controllers.

Two main classes of signals are sent during locomotion from the spinal limb controllers to the supraspinal motor centers: (1) sensory signals from limb mechanoreceptors reflect- 
Table 2. Classification of hindlimb neurons $(n=37)$

\begin{tabular}{lccll}
\hline $\begin{array}{l}\text { Groups and } \\
\text { subgroups }\end{array}$ & $\begin{array}{l}\text { Number of } \\
\text { neurons }^{a}\end{array}$ & $\begin{array}{l}\text { Percent of } \\
\text { neurons }^{a}\end{array}$ & $\begin{array}{l}\text { Tests with CC }>0.6 \\
\text { relative to 2F2H }\end{array}$ & $\begin{array}{l}\text { Sources of } \\
\text { modulation }^{b}\end{array}$ \\
\hline $1-1$ & $7(4)$ & $18.9(10.8)$ & $2 \mathrm{H}, 2 \mathrm{R}$ & $\mathrm{HR}$ \\
$1-3$ & $4(2)$ & $10.8(5.4)$ & $2 \mathrm{H}$ & $\mathrm{HR}+\mathrm{HL}$ \\
$2-1$ & $5(4)$ & $13.5(10.8)$ & $2 \mathrm{H}, 2 \mathrm{~F}, 2 \mathrm{R}$ & $\mathrm{HR} / \mathrm{FR}$ \\
$2-3$ & $3(1)$ & $8.1(5.4)$ & $2 \mathrm{H}, 2 \mathrm{~F}$ & $\mathrm{FR}+\mathrm{FL} / \mathrm{HR}+\mathrm{HL}$ \\
$2-4$ & $1(0)$ & $2.7(0.0)$ & $2 \mathrm{H}, 2 \mathrm{~F}, 2 \mathrm{~L}$ & $\mathrm{HL} / \mathrm{FL}$ \\
$3-1$ & $4(2)$ & $10.8(5.4)$ & $2 \mathrm{R}$ & $\mathrm{HR}+\mathrm{FR}$ \\
$3-3$ & $11(6)$ & $29.7(16.2)$ & - & $\mathrm{FR}+\mathrm{FL}+\mathrm{HR}+\mathrm{HL}$ \\
$3-4$ & $2(2)$ & $5.4(5.4)$ & $2 \mathrm{~L}$ & $\mathrm{HL}+\mathrm{FL}$ \\
\hline
\end{tabular}

${ }^{a}$ Number or percentage of antidromically identified neurons is indicated in parentheses.

${ }^{b}$ Convergence of inputs necessary for generating the modulation pattern similar to that in control is indicated by a plus sign. Equivalence of inputs (or of their combinations) is indicated by a slash.
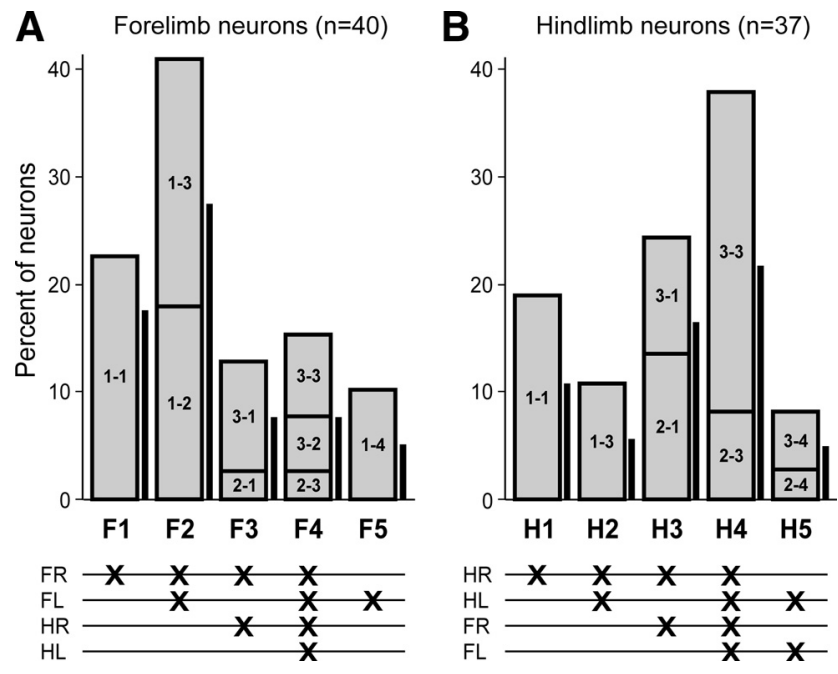

Figure 12. Sources of modulation of motor cortex neurons. The bottom panels in $\boldsymbol{A}$ and $\boldsymbol{B}$ show the combinations of inputs from different limb controllers influencing forelimb and hindlimb populations of motor cortex neurons, respectively. FR, FL, HR, and $H L$ are the controllers of right and left forelimbs and right and left hindlimbs, respectively. Each cross indicates input from the corresponding controller to the neurons of left motor cortex. In the upper panels, the height of the bars indicates the percentage of left motor cortex neurons with a given combination of inputs. Five functional groups of forelimb neurons (F1-F5) and five functional groups of hindlimb neurons ( $\mathrm{H} 1-\mathrm{H} 5)$ were found. For each of these groups, the contribution of different subgroups of neurons (termed as in Tables 1 and 2) is indicated by dividing the bar into corresponding parts. For each group of neurons, the proportion of antidromically identified neurons (PTNs) is shown by the thick vertical line near the bar.

ing limb movements, and (2) "efference copy" signals reflecting activity of the central pattern generator (CPG) (see e.g., Orlovsky et al., 1999). When the limb is standing, the flows of signals of both classes change radically. For the sensory signals, these changes are caused by cessation of stepping limb movements, as well as by a considerable reduction of the periodic modulation of muscle activity. For the efference copy signals, the changes are caused by considerable reduction or almost complete cessation of the CPG activity, signified by a dramatic decrease of the periodic input to most motoneurons (reflected in EMGs). Thus, during bipedal locomotion, each limb controller can send signals to the cortex that are either similar to those sent during quadrupedal locomotion (if the limb is stepping), or very different (if the limb is standing).

With these considerations in mind, we have compared the phase activity histograms obtained from each individual neuron during quadrupedal and bipedal locomotion, to reveal the limb controllers contributing to periodic modulation of this neuron. To evaluate similarity of the two curves, we calculated the CC between them. This analysis allows revealing covariations of the instantaneous discharge frequency within the cycle. The CC does not reflect differences in the mean frequency or in the coefficient of modulation, but it does reflect differences in the preferred phases and general discharge pattern.

To choose the critical value of CC separating similar and nonsimilar pairs of histograms, we took into account the results of our analysis of the similarity between kinematical and EMG profiles of quadrupedal and bipedal tests (Figs. 5, 6). It was shown that CC was $>0.7$ if the limb was walking in a bipedal test, and $<0.5$ if the limb was standing. Based on these findings, the critical CC level was set at 0.6 .

The analysis revealed five groups of forelimb area neurons (F1-F5) and five groups of hindlimb area neurons (H1-H5) differing in combinations of limb controllers that drive the neuronal discharges (Fig. 12). The vast majority of neurons (79\%) received inputs from two or even all four limbs in different combinations. The input from the corresponding contralateral limb was present in the overwhelming majority of neurons $(88 \%)$. This explains considerable changes in general characteristics of neuronal activity in those tasks in which that limb did not walk (Figs. 8, 9). However, only about $20 \%$ of neurons received modulating inputs exclusively from the corresponding contralateral limb (groups F1 and $\mathrm{H} 1$ ). The populations of forelimb and hindlimb area neurons considerably differed in the proportion of different inputs: while only $30 \%$ of the forelimb area neurons received inputs from the hindlimb controllers, $70 \%$ of the hindlimb area neurons received inputs from the forelimb controllers; there were also differences in proportions of inputs from the ipsilateral limb of the same girdle.

We want to note that, although the existence of diverse input patterns to different motor cortex neurons clearly emerges from this study, the exact sizes of the neuronal groups with particular input patterns can be only roughly estimated here because of a relatively small neuronal sample. Also, the differentiation of activity of PTNs and nonidentified neurons was not the focus of the study and awaits further investigation.

The results of this study have shown that, during locomotion, a representation of each limb in the motor cortex receives signals about activity of all limb controllers. Similar results were obtained for the cat during reaching: the activity of mechanisms controlling limb reaching was reflected in the cortical representation of the opposite limb performing postural function (Putrino et al., 2010). It was suggested that interhemispheric connections are responsible for these influences.

The diversity of modulating inputs to motor cortex neurons suggests different functional roles for these neurons. We will consider their possible function in a conceptual framework of relatively independent limb controllers, which are coordinated due to their interactions (for review, see Orlovsky et al., 1999). Correspondingly, motor cortex neurons can contribute to the generation of stepping movements of individual limbs ("intralimb coordination"), to the maintenance of definite phase relations between the stepping limbs ("interlimb coordination"), or to both functions. During simple locomotion, this coordination may be not very important, as cortical activity is not necessary for this behavior. However, during those locomotion tasks that require descending cortical commands, such as walking on a cluttered surface, both intralimb and interlimb coordination may be critical to ensure seamless incorporation of these commands into the ongoing pattern of locomotion. We suggest the following 
coordinative functions for different groups of motor cortex neurons:

(1) In the forelimb area neurons of group F1 and the hindlimb area neurons of group $\mathrm{H} 1$, the modulation was determined exclusively by the contralateral forelimb or hindlimb controller, respectively. These neurons could be involved in the intralimb motor coordination.

(2) The neurons of groups $\mathrm{F} 2, \mathrm{~F} 5$, and $\mathrm{H} 2$ received modulating inputs from the ipsilateral limb of their girdle. They could be involved in the interlimb coordination within their own girdle.

(3) The neurons of groups $\mathrm{F} 3, \mathrm{~F} 4, \mathrm{H} 3, \mathrm{H} 4$, and $\mathrm{H} 5$ received modulating inputs from the controllers of both girdles. They could be involved in the coordination between the two girdles. In total, relative size of these groups was much larger in the hindlimb population than in the forelimb population (Fig. 12). This difference corresponds well to the leading functional role of the forelimb controllers during some forms of locomotion (e.g., Shik and Orlovsky, 1965).

To conclude, during locomotion the motor cortex sends periodical, step-related signals to the spinal cord. To understand their functions, it is necessary to reveal the origin of these signals and their motor effects. The first question was addressed in the present study. It was found that diverse combinations of inputs from limb controllers contribute to the step-related frequency modulation in individual cortical neurons. From these data, we suggest that motor cortex neurons participate in intralimb coordination, i.e., in generation of stepping movements, as well as in coordination of the right and left limbs within each of the girdles; in addition, the majority of hindlimb neurons also participate in coordination of movements of the hindlimbs with those of the forelimbs.

\section{References}

Armstrong DM, Drew T (1984a) Discharges of pyramidal tract and other motor cortical neurons during locomotion in the cat. J Physiol 346: 471-495.

Armstrong DM, Drew T (1984b) Locomotor-related neuronal discharges in cat motor cortex compared with peripheral receptive fields and evoked movements. J Physiol 346:497-517.

Armstrong DM, Drew T (1985) Electromyographic responses evoked in muscles of the forelimb by intracortical stimulation in the cat. J Physiol 367:309-326.

Arshavsky YI, Berkinblit MB, Fukson OI, Gelfand IM, Orlovsky GN (1972) Recordings of neurons of the dorsal spinocerebellar tract during evoked locomotion. Brain Res 43:272-275.

Arshavsky YI, Gelfand IM, Orlovsky GN, Pavlova GA, Popova LB (1984) Origin of signals conveyed by the ventral spino-cerebellar tract and spinoreticulo-cerebellar pathway. Exp Brain Res 54:426-431.

Arshavsky YI, Gelfand IM, Orlovsky GN (1986) Cerebellum and rhythmical movements. New York: Springer.

Asanuma H, Larsen KD, Yumiya H (1979) Receptive fields of thalamic neurons projecting to the motor cortex in the cat. Brain Res 172:217-228.

Beloozerova IN, Sirota MG (1985) Activity of neurons of the motosensory cortex during natural locomotion in the cat. Neirofiziologiia $17: 406-408$

Beloozerova IN, Sirota MG (1988) Role of motor cortex in control of locomotion. In: Stance and motion. Facts and concepts (Gurfinkel VS, Ioffe ME, Massion J, Roll JP, eds), pp 163-176. New York: Plenum.

Beloozerova IN, Sirota MG (1993a) The role of the motor cortex in the control of accuracy of locomotor movements in the cat. J Physiol 461:1-25.

Beloozerova IN, Sirota MG (1993b) The role of the motor cortex in the control of vigor of locomotor movements in the cat. J Physiol 461:27-46.
Beloozerova IN, Sirota MG (2002) Activity of ventrolateral thalamus (VL) during locomotion. Soc Neurosci Abstr 28:62.13.

Beloozerova IN, Sirota MG (2003) Integration of motor and visual information in the parietal area 5 during locomotion. J Neurophysiol 90:961-971.

Beloozerova IN, Sirota MG, Orlovsky GN, Deliagina TG (2005) Activity of pyramidal tract neurons in the cat during postural corrections. J Neurophysiol 93:1831-1844.

Bishop PO, Burke W, Davis R (1962) The identification of single units in central visual pathways. J Physiol 162:409-431.

Craig AD (2008) Retrograde analyses of spinothalamic projections in the macaque monkey: input to the ventral lateral nucleus. J Comp Neurol 508:315-328.

Drew T (1988) Motor cortical cell discharge during voluntary gait modification. Brain Res 457:181-187.

Drew T (1991) The role of the motor cortex in the control of gait modification in the cat. In: Neurobiological basis of human locomotion (Shimamura M, Grillner S, Edgerton VR, eds), pp 201-212. Tokyo: Japan Scientific Societies.

Drew T (1993) Motor cortical activity during voluntary gait modifications in the cat. I. Cells related to the forelimbs. J Neurophysiol 70:179-199.

Drew T, Jiang W, Kably B, Lavoie S (1996) Role of the motor cortex in the control of visually triggered gait modifications. Can J Physiol Pharmacol 74:426-442.

Drew T, Prentice S, Schepens B (2004) Cortical and brainstem control of locomotion. Prog Brain Res 143:251-261.

Fuller JH, Schlag JD (1976) Determination of antidromic excitation by the collision test: problems of interpretation. Brain Res 112:283-298.

Ghosh S (1997) Identification of motor areas of the cat cerebral cortex based on studies of cortical stimulation and corticospinal connections. J Comp Neurol 380:191-214.

Karayannidou A, Deliagina TG, Tamarova ZA, Sirota MG, Zelenin PV, Orlovsky GN, Beloozerova IN (2008) Influences of sensory input from the limbs on feline corticospinal neurons during postural responses. J Physiol 586:247-263.

Karayannidou A, Beloozerova IN, Zelenin PV, Stout EE, Sirota MG, Orlovsky GN, Deliagina TG (2009) Activity of pyramidal tract neurons in the cat during standing and walking on an inclined plane. J Physiol 587:3795-3811.

Krouchev N, Kalaska JF, Drew T (2006) Sequential activation of muscle synergies during locomotion in the intact cat as revealed by cluster analysis and direct decomposition. J Neurophysiol 96:1991-2010.

Mori A, Waters RS, Asanuma H (1989) Physiological properties and patterns of projection in the cortico-cortical connections from the second somatosensory cortex to the motor cortex, area 4 gamma, in the cat. Brain Res 504:206-210.

Myasnikov AA, Dykes RW, Leclerc SS (1997) Correlating cytoarchitecture and function in cat primary somatosensory cortex: the challenge of individual differences. Brain Res 750:95-108.

Nieoullon A, Rispal-Padel L (1976) Somatotopic localization in cat motor cortex. Brain Res 105:405-422.

Orlovsky GN (1970) Work of the reticulo-spinal neurons during locomotion. Biophysics 15:761-771.

Orlovsky GN (1972a) Activity of rubrospinal neurons during locomotion. Brain Res 46:85-98.

Orlovsky GN (1972b) Activity of vestibulospinal neurons during locomotion. Brain Res 46:99-112.

Orlovsky GN, Deliagina TG, Grillner S (1999) Neuronal control of locomotion. From mollusc to man. New York: Oxford UP.

Prilutsky BI, Sirota MG, Gregor RJ, Beloozerova IN (2005) Quantification of motor cortex activity and full-body biomechanics during unrestrained locomotion. J Neurophysiol 94:2959-2969.

Putrino D, Mastaglia FL, Ghosh S (2010) Neural integration of reaching and posture: interhemispheric spike correlations in cat motor cortex. Exp Brain Res 202:765-777.

Rasmussen S, Chan AK, Goslow GE Jr (1978) The cat step cycle: electromyographic patterns for hindlimb muscles during posture and unrestrained locomotion. J Morph 155:253-269.

Rossignol S (1996) Neural control of stereotypic limb movements. In: 
Handbook of physiology, Sec 12 (Rowell LB, Sheperd JT, eds), pp 173216. New York: Oxford UP.

Shik ML, Orlovsky GN (1965) Coordination of the limbs during running of the dog. Biophysics 10:1148-1159.

Shik ML, Orlovsky GN (1976) Neurophysiology of locomotor automatism. Physiol Rev 56:465-501.

Trank TV, Chen C, Smith JL (1996) Forms of quadrupedal locomotion. I. A comparison of posture, hindlimb kinematics, and motor patterns for normal and crouched walking. J Neurophysiol 76:2316-2326.

Vicario DS, Martin JH, Ghez C (1983) Specialized subregions in the cat motor cortex: a single unit analysis in the behaving animal. Exp Brain Res 51:351-367.

Waters RS, Favorov O, Asanuma H (1982) Physiological properties and pattern of projection of cortico-cortical connections from the anterior bank of the ansate sulcus to the motor cortex, area 4 gamma, in the cat. Exp Brain Res 46:403-412.

Widajewicz W, Kably B, Drew T (1994) Motor cortical activity during voluntary gait modifications in the cat. II. Cells related to the hindlimbs. J Neurophysiol 72:2070-2089.

Yen CT, Honda CN, Jones EG (1991) Electrophysiological study of spinothalamic inputs to ventrolateral and adjacent thalamic nuclei of the cat. J Neurophysiol 66:1033-1047.

Zar JH (1974) Biostatistical analysis. Englewood Cliffs: Prentice-Hall.

Zelenin PV, Deliagina TG, Orlovsky GN, Karayannidou A, Stout EE, Sirota MG, Beloozerova IN (2010) Activity of corticospinal neurons in the cat during different forms of locomotion. $7^{\text {th }}$ FENS Forum of European Neuroscience. 053.12 